\title{
Progressive Crushing of Polymer Matrix Composite Tubular Structures: Review
}

\author{
Ali Rabiee, Hessam Ghasemnejad \\ Centre for Structures, Assembly and Intelligent Automation, Cranfield University, Cranfield, UK \\ Email: a.rabiee@cranfield.ac.uk, hessam.ghasemnejad@cranfield.ac.uk
}

How to cite this paper: Rabiee, A. and Ghasemnejad, H. (2017) Progressive Crushing of Polymer Matrix Composite Tubular Structures: Review. Open Journal of Composite Materials, 7, 14-48. https://doi.org/10.4236/ojcm.2017.71002

Received: September 29, 2016

Accepted: January 13, 2017

Published: January 16, 2017

Copyright $\odot 2017$ by authors and Scientific Research Publishing Inc. This work is licensed under the Creative Commons Attribution International License (CC BY 4.0).

http://creativecommons.org/licenses/by/4.0/

(c) (i) Open Access

\begin{abstract}
The present paper reviews crushing process of fibre-reinforced polymer (FRPs) composites tubular structures. Working with anisotropic material requires consideration of specific parameter definition in order to tailor a well-engineered composite structure. These parameters include geometry design, strain rate sensitivity, material properties, laminate design, interlaminar fracture toughness and off-axis loading conditions which are reviewed in this paper to create a comprehensive data base for researchers, engineers and scientists in the field. Each of these parameters influences the structural integrity and progressive crushing behaviour. In this extensive review each of these parameters is introduced, explained and evaluated. Construction of a well-engineered composite structure and triggering mechanism to strain rate sensitivity and testing conditions followed by failure mechanisms are extensively reviewed. Furthermore, this paper has mainly focused on experimental analysis that has been carried out on different types of FRP composites in the past two decades.
\end{abstract}

\section{Keywords}

Crashworthiness, Fibre-Reinforced Polymer Composites (FRPs), Metal Tube

\section{Introduction}

Axial crushing of metal tubes has been studied by vast majority of researches. Metal tubes have energy absorption mechanism of plastic deformation due to progressive folding formation [1]. Some researcher increased wall thickness to increase mass volume energy absorption ratio [2] [3], and furthermore for better energy absorption, foam filled aluminium and stainless steel tube were introduced [4]. Other researchers introduced metals in inner core of sacrificial cladding structures [5] [6] [7]. However, due to high expense of material, manufacturing and maintenance for metals and also heavier sacrificial structure, these types of structures were found insufficient [8] [9]. Alternatively, in terms of specific energy absorption and weight reduction polymer composite materials are comparatively introduced to improve structural energy absorp- 
tion capabilities as well as further weight reduction [10] [11].

In passenger carrying application such as aerospace and automotive where weight concerning application is an important factor, these improvements are no longer relevant due to fuel consumption. Consequently, fibre reinforced polymer (FRP) composites have been extensively studied due to weight to stiffness in comparison with metals [12] [13]. Researchers concluded that a well-engineered FRP composite structure would be an appropriate choice where energy absorption is concerned [14] [15] [16]. Composite materials such as carbon fibre reinforced polymer and glass fibre reinforced polymer encounter fractures in axial crushing to absorb energy unlike metals which absorbs energy by plastic deformation [17] [18]. Savona CS [15] stated that the majority of energy absorption is obtained through failure modes of Mode I and Mode II fracture, frond bending, fibre fracture and also friction at crushed fronds [19].

One of the main factors that FRP composite materials are commonly used in high performance automotive and airframe substructures is having capabilities of highenergy absorption. The structural elements used in high performance automotive and aerospace applications are mainly from FRP composites, which are economically beneficial due to weight reduction and lower fuel consumption. Furthermore, FRP composite materials provide enhanced level of structural vehicle crashworthiness that ensures high-energy absorption in sudden collision in a controlled progressive collapse. This is dominated as a result of extensive fracture mechanisms [17] [20] [21] [22].

FRP composite materials are known for being tailored to improve material properties based on specific applications with high specific strength and verification of fibre and matrix, and fibre orientations. This factor makes this type of materials more advanced compared to more conventional isotropic materials.

There are several ways to absorb impact energy. Deformation of solids is usually based on plastic flow, although appreciable amounts of energy can be absorbed by controlled brittle fracture mechanisms. Absorbers can also be reusable like a hydraulic damper; rechargeable with the energy absorbing component being replaced in a permanent container; or expandable, as in the collapse of a vehicle structure during a crash. Composite materials have a significant potential for kinetic energy absorption during a crash. The application of energy absorbers depends on the type of impact load. This can be distributed over the whole impact body, as in explosion loading, or it can be localised, with a small or pointed body hitting a large body. The large body may deform in an overall manner in the same way as if the load were distributed, or the small body may penetrate it locally.

Other studies [10] [23] [24] investigated the parameters that influence composite tubes crushing performance. Higher energy absorption is yielded by progressive crushing process which depends on mechanical properties, fibre orientation, laminate stacking sequence, fibre and resin volume fractions, and the geometry of the tube. However, different levels of the specific energy absorption for the same parameters can be achieved by only altering the geometry of composite structures [17]. Various dimensions affecting the energy absorption were studied [25] [26] for square and circular composite tubes. It is concluded from experimental studies that the $D / t$ ratio of these composite tubes significantly affects energy absorption capability. Thornton et al. [27] 
[28] stated that circular cross sectional composite tubes perform better compared to square and rectangular cross sectional composite tubes. Similar conclusion was also reported by Mamalis et al. [29] [30] that circular cross sectional composite tubes demonstrated a better performance in energy absorption capability. Jimenez et al. [31] investigated "I" sectional tubes. Based on the study square cross sectional composite tube absorbed 15\% more energy compared to "I" section profile. Mamalis et al. [32] [33] [34] studied conical shells on their specific energy absorption capabilities, and concluded that specific energy absorption decreases by increase of semi-apical angle of the frusta. Many researchers [17] [24] [32] [33] [34] [35] [36] conducted experiments on energy absorption of composite tubes both circular and square cross sections. It was concluded that geometrical shape significantly influences the energy absorption capability of composite structures.

Farley and Jones [29] [37] studied various layup orientations on the carbon/epoxy composite tubes. According to their results, as lateral angle increases, the specific energy absorption decreases. An improvement of $10 \%-30 \%$ in specific energy absorption corresponded to include angle reduction from $180^{\circ}$ to $90^{\circ}$. Elgalai et al. [38] studied carbon/epoxy and glass/epoxy composite tubes for their crush response under quasistatic axial loading.

Energy absorption capability of composite tubes reported to be enhanced by corrugation. Zarei et al. [39] investigated and experimented on hexagonal box with vertical ribs for their energy absorption capabilities using woven fibre glass/polyamide plates with thermoforming welding method. Abdewi et al. [40] studied radial corrugated glass/epoxy composite tubes both at quasi-static axial and lateral crushing. The conclusion of these studies stated that radial corrugation significantly influences the energy absorption of composite tubes.

Extensive experimental researches have been carried out on the effects of fibre orientations in composite fabrication on axial crushing behaviour. Carroll et al. and Mahdi et al. [41] [42] [43] carried out an investigation on filament-wound glass fibre/epoxy with ply orientations of $\pm 55^{\circ}$ under quasi-static compression, and reported that failure depends on rate of loading and stress ratio. Strength and stiffness were implied to be a function of loading direction and stress strain behaviour influenced the total energy absorption. It was also suggested that ply orientations of $( \pm 0)$ and $( \pm 90)$ of carbon/ epoxy fibre are able to crush more progressively and absorb more energy in comparison with $( \pm 45)[7]$.

In axial crushing the aspect ratio of geometrical parameters were also studied. Mamalis et al. [19] studied the effect of $\mathrm{L} / \mathrm{w}$ (length/inner width) ratio on axial crushing capability and concluded that as the aspect ratio of compressed tube increases, the peak load $\left(F_{\max }\right)$ decreases. Palanivelu et al. [44] showed that crushing state was influenced by aspect ratio of $t / d$ or $t / w$ (wall thickness/outer diameter or width) of 0.045 in different shape i.e. both geometries of square and round tube crushed progressively, although catastrophic crush in square tube was observed, however in aspect ratio of 0.083 both shapes were progressively crushed [45]. It is proven that progressive crushing for composite tubes of circular cross section can be obtained by $t / D$ ratio of $0.015-0.25$ whereas $t / D$ ratio of less than 0.015 results into catastrophic failure [46]. 
The energy absorption capability of composite materials offers an exceptional combination of structural weight reduction and vehicle safety improvement with providing an equivalent or higher crash resistance compared to metallic structures. In automotive industry the basic occupant crash protection since 1950s has been used to optimise crash safety and ever since it became the priority of any car design requirement. The study of first structural design requirements in aeronautical industry were crash protection in military helicopters and light flexing aircraft that were in crash survival design guide forms [47]. In aerospace application the material structures considered are high performing materials including epoxy resins reinforced glass fibres, and increasingly, carbon and aramid fibres on hybrids composites. In automotive field reinforced polymers must meet a complex set of design requirements among other crash energy absorption management in front-end and side of the car structures [48] [49] [50].

This paper, reviews the influence of various parameters on progressive crushing. Most review papers focus on one or two parameters whereas this paper focuses on the most critical parameters and covering mostly all parameters that could potentially alter progressive crushing behavior of composite structures. Anisotropic materials are nonlinear and by consideration of the parameters introduced, explained and evaluated in this paper, a well-engineered composite structure can be tailored. This paper undergoes evaluation of well-engineered composite structure, followed by different trigger mechanism. Moving on to different aspect of strain rate sensitivity and loading parameters, followed by extensive evaluation of failure mechanism and interlaminar fracture toughness. Simply, composite structure design, testing conditions, and failure mechanisms are extensively reviewed.

The following sections are structured initiating from introduction of crushing behavior criteria and gradually moving on to factors effecting energy absorption capabilities and different failure modes. The paper then initiates with effect of fibre and matrix on energy absorption capabilities followed by laminate design, geometry. These criteria are sensitives; a simple alteration can lead to change in material behaviour. Trigger mechanism enables to initiate failure and avoid local buckling. At this stage a detailed review of composite structure from tailoring and triggering is complete and testing begins. Different types of strain rate and loading conditions are introduced and evaluated, followed by different types of failure mechanisms. Theoretical analysis is introduced to predict energy absorption followed by crashworthy of composite box structures. The last section is spent on interlaminar fracture toughness, this is accompanied by various fracture mechanism of interalaminar and interlaminar, which is a great evaluation of progressive failure modes that leads to high energy absorption capabilities of composite structures.

\section{Valuation Criteria for Crushing Behaviour}

In the study of energy absorption capabilities of FRP composite materials, important variables such as manufacturing process and method, microstructures, specimen geometry, crush initiator and trigger mechanisms, and crushing rate are investigated. Specific energy absorption (SEA) performance is considered to be of the most impor- 
tant parameters of specimens crushing material or collapsing or structural parts. SEA value is the relation between energy absorption compared to the absorber's mass or structure. Consequently, it becomes critically important for lightweight designs. Study of energy absorption for energy management capabilities is another critical factor, which is the shape of the force-crush distance curve. Identification of one measure is used to mark and indicate the shape of the curve, which is known as crush-force efficiency (CFE). This value relates the average crush force $\left(F_{m}\right)$ to the maximum force $\left(F_{\max }\right)$ of the crush characteristic.

Within the initiation phase the highest force normally occurs. Absorbers with rectangular shape of force-crush distance curve demonstrate a crush force efficiency of $100 \%$. It is not optimum to have the maximum force to be substantially larger than the average crush force, due to energy management's goal of absorbing all the energy without conveying or transmitting large amount of force to the passengers.

Another parameter in energy absorption management is stroke efficiency (SE), which is the ratio of initial length of the absorber to the stroke at 'bottoming out' and high ratios specify high efficiency of material used.

\section{Factors Affecting Energy Absorption Capability}

In this section several variables related to energy absorption of composite thin-walled components are reviewed. In composite materials, design with constituent material properties and reach macro-mechanical properties by micromechanics analysis [21]. Regarding different applications of composite materials, their suitability is defined by impact properties and energy absorption properties and then usual design parameters.

However, composite material constituent phases and the laminate layup is crucial in crashworthiness capability of composite structures as it effectively changes the mechanical property of the final product. Temperature is another important factor, which has considerable effects on material crashworthy response.

Quasi-static compression or impact loading is carried out in axial crushing. In static loading the crushing speed is within a range of 1 to $11 \mathrm{~mm} / \mathrm{s}$, normally a composite tube is compressed between two plates (crossheads) of one being hydraulic press. In dynamic impact loading a drop hammer or an impactor is used. To avoid buckling, specimen dimensions are determined based on the preliminary calculation [51]. Different shapes and geometries such as round, square, hexagon [44], cones [51], and plates [13] are used for instance. A typical specimen length is within a range of $50-125$ $\mathrm{mm}$ in length, $20-100 \mathrm{~mm}$ in outside diameter or width and wall thickness of $1-3$ $\mathrm{mm}$.

In crushing event energy absorption capability is calculated to work out the specific energy dissipation rate. In composite crushing total work $\left(W_{T}\right)$ that indicates the energy absorption capability is equal to the area under the load-displacement curve,

$$
W_{T}=\int F \mathrm{~d} s
$$

where $F$ is the corresponding force on the structure and $s$ is the cross-head distance.

Specific Energy Absorption (SEA) is energy absorption capability, which is calculated as per unit mass absorbed. 


$$
\mathrm{SEA}=\frac{W_{T}}{m}=\frac{W_{T}}{q v}
$$

where $m$ is crushed mass, $q$ is the material density, and $v$ is the volume of crushed specimen.

In prior of material failure under buckling such as global buckling, local buckling, fracture or yield or progressive crushing peak load is measured [52]. Further buckling failure can lead to either catastrophic or progressive failure [53] where it illustrated on load displacement curve, where the area under the curve represents the total energy absorption. In occurrence of progressive failure, a larger area under the curve is gained with a progressive constant load with increase of crushing displacement.

Catastrophic failure leads to rapid load drop and lower energy absorption. This is due to specimen crush being from fracture in mid-plane [54] or longitudinal cracks [44]. Progressive failure results into higher energy absorption due to a combination of multi-failure modes initiated during crush such as local buckling, Mode I, Mode II, and Mode III [55]. More energy absorption is obtained from Mode I, Mode II, splaying mode and sliding mode respectively [56] due to bending and friction between ply laminates [13]. Fibre orientations influence the energy absorption in Mode I interlaminar fracture [57]. In study of Mode III although lower energy absorption is obtained of compressed tubes due to fracture in mid-plane and unstable collapse [19], this contradicts with another study that stated failure in Mode III is due to fibre fracture and matrix deformation that progressively extends through elliptical structure with ratio of 2 , which resulted into higher specific energy absorption [55].

\subsection{Fibre and Matrix Materials}

The vast majority of literatures on crashworthiness of composites are focused on fibres of carbon, glass or aramid in thermosetting resin for instance epoxy. Farley [58], Thornton [59], Schmueser and Wickliffe [60] and Farley and Jones [61] all extensively experimented and compared energy absorption capabilities of various specimens made of glass, carbon and aramid epoxy. Hybrid composites were investigated to combine different types of fibres into a single laminate to optimise the energy absorption characteristics. Thornton and Edwards [62] stated that hybrids of glass-aramid and carbon-aramid cause an unstable folding collapse that would not have occurred if the specimens were composed of glass or carbon fibres alone. New fibre and matrix materials such as Dyneema PE fibre/carbon fibre hybrid [63] have been introduced to improve specific energy absorption capabilities. The majority of these investigations have been carried out with thermosetting matrix materials, usually an epoxy. Other thermoplastic matrix materials such as polyester and polyetheretherketone (PEEK) have been used as matrix material [64] [65].

Hamada et al. [65] conducted a study on the usage of a thermoplastic polyetheretherketone (PEEK) matrix with fibre carbon which concludes an outstandingly high specific energy absorption value of $180 \mathrm{~kJ} / \mathrm{kg}$. This value of energy absorption is even more than a double value of carbon-epoxy. This is credited to PEEK matrix that has high resistance towards crack growth between the fibres, which prevents failure and results into stable progressive crushing [66]. 


\subsection{Laminate Design}

In this section several variables related to energy absorption of composite thin-walled components are reviewed. In composite materials, design with constituent material properties and reach macro-mechanical properties by micromechanics analysis [21]. Regarding different applications of composite materials, their suitability is defined by impact properties and energy absorption properties and then usual design parameters.

However, composite material constituent phases and the laminate layup is crucial in crashworthiness capability of composite structures as it effectively changes the mechanical property of the final product. Temperature is another important factor, which has considerable effects on material crashworthy response. Various reports have been extensively concentrated on the effects of laminate design on energy absorption of composite structures. Thornton and Edwards [62] showed, in a stable collapse a $[ \pm 45 / \pm 45]_{n}$ layup resulted into obtaining lower energy absorption value than $[0 / 90]_{n}$ lay-ups. Furthermore, the specific energy absorption generally increases in $[0 / 90]$ aramid-epoxy and glass-epoxy circular tubes for $45^{\circ}<\theta<90^{\circ}$, with increasing of $\theta$. Schmueser and Wickliffe [60] showed variations in specific energy absorption of carbon-epoxy, glass-epoxy and aramid-epoxy $\left[0_{2} / \pm \theta\right]$ specimens all generally increase with increasing $\theta$. Mamalis et al. [67] worked on different materials with various thin-walled circular and square tubes, and reported specimens made of a commercial glass fibre and vinyl ester composite material which consists of nine plies in the sequence of $\left[\left(90 / 0 / 2 R_{c}\right) /\left(2 R_{c} / 0 / 90\right) / R_{c .75}\right]$, show better energy absorption behaviour than those made of a glass fibre composite material in which the glass fibres were in the form of chopped-strand mat with random fibre orientation in the plane of the mat. Hamada et al. [64] reported that the specific energy absorption for $0^{\circ}$ carbon/PEEK tubes was due to high fracture toughness of PEEK.

Woven composites introduce a different approach to the fabrication of thick sections for use in primary and secondary structural applications. Interlacing two mutually perpendicular sets of yarn shapes woven composites. The lengthwise clothes are called warp and the crosswise clothes are known as fill or weft (see Figure 1).

Warp and weft's interlacing pattern are known as weave. The fundamental twodimensional weaves are plain, twill and satin, where it provides more balanced properties in the fabric plane than a unidirectional laminate [68] [69] [70] [71]. The interlacing of fibre bundles in woven composites can often increase out-of-plane strength as in the case of three-dimensional woven fabrics. Woven fabrics are thicker than unidirectional lamina; therefore, fabrication of thick composites is less insensitive and less prone to assembly error.

The property improvements are achieved through in-plane stiffness and strength properties. The weave architecture influences the loss of in-plane stiffness and strength. This architecture is complex and therefore several parameters control the mechanical and thermal properties of woven composites. The classical laminate theory cannot be used to predict the mechanical properties of woven composite due to many specific factors including the density of the fibre bundles, the type of the weaving and the curvature that are essential to be considered [72]. Furthermore, the composite structure manufacturing is rather irregular in woven composite that can be eliminated in a 

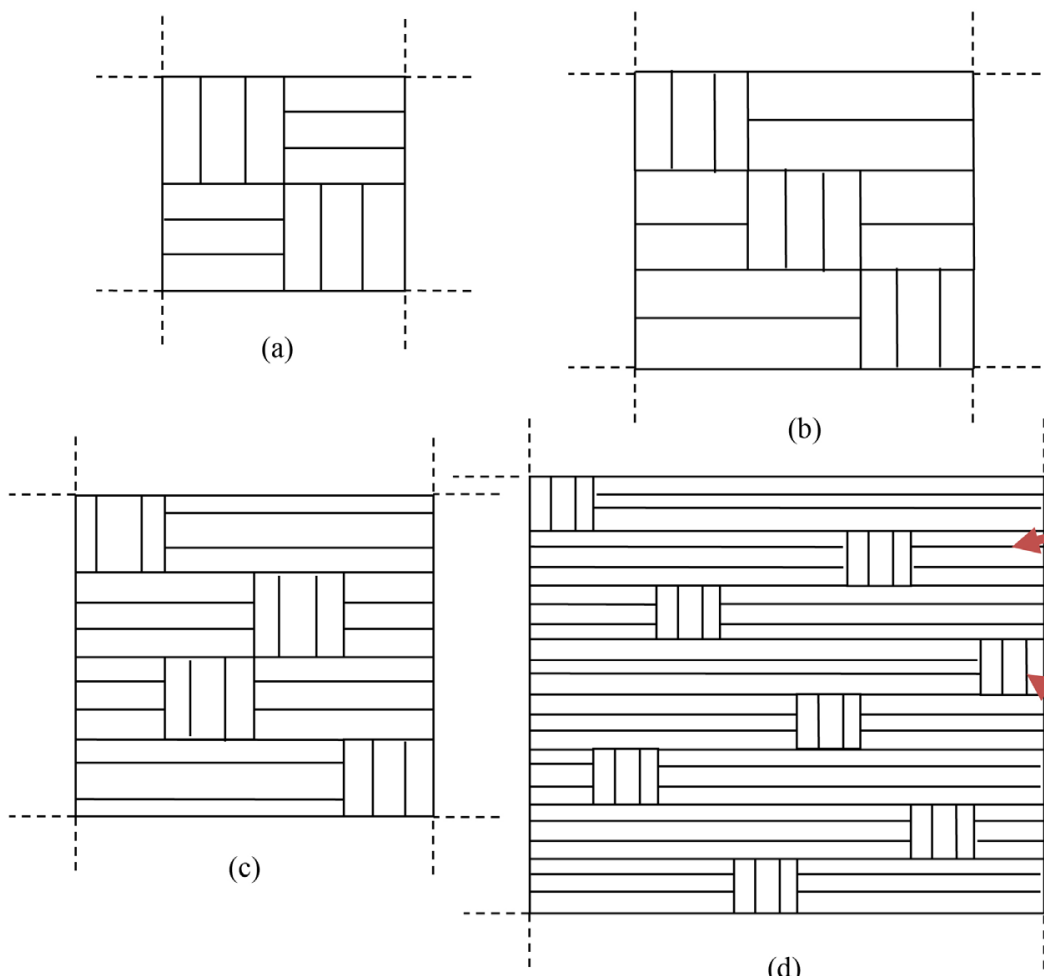

(b) Warp

Figure 1. 2D-Weave composites: (a) plain, (b) twill, (c) 4-harness, and (d) 8-harness [57].

non-woven laminate.

In brief, two approaches that are usually employed to study non-woven composite laminates are micromechanics, and macromechanics. In micromechanics study, the mechanical properties of laminate are studied in details as (fibre, matrix and interface), while the macromechanics detects the material properties of laminate as a whole. Another approach, which is an intermediate of study, is called mesomechanics. This approach is provided to consider the mechanical properties of weave [73]. The major problem in the study of mesomechanics is the large variety of textile performs that are employed including weaves, braids, knits, mats, properties of weave stitched fabrics and two-dimensional or three dimensional.

\subsection{Structural Geometry}

Extensive research was carried out based on the effect of various type of specimen geometry on the energy absorption capability by varying the shell geometric parameters such as wall thickness, $t$, axial length, $L$, mean diameter, $D$, or circumference, $C$ [21]. Farley [74] reported the energy absorption capability of diameter to thickness, $D / t$, ratio for carbon-epoxy and aramid-epoxy circular tubes are a non-linear function. Furthermore, Farley reported that carbon-epoxy tubes are dependent on $D / t$ for tubes with various internal diameters. Mamalis et al. [50] indicated that energy absorption of glass polyester circular tubes in static axial loading increases with increasing $t / D$. Thornton and Edwards [62] concluded that the energy absorption of square and rectangular cross-section tubes is less than circular ones. The primary reason for this energy absorption reduction is due to the corners and the edges response to stress con- 
centration leading to the formation of splitting cracks.

Axial crushing with cross sectional shape, Palanivelu et al. [44] investigated shapes of square and hexagonal with $t / D$ or $t / W$ aspect ratio of 0.045 and reported catastrophic failure whereas circular shape crushed progressively and uniform. An increase in aspect ratio to 0.083 resulted into progressive crushing mode for square and hexagonal shapes. This increase also resulted into higher SEA value of $30.4 \mathrm{~kJ} / \mathrm{kg}$ in circular shape compared with square with $12.3 \mathrm{~kJ} / \mathrm{kg}$ and hexagonal $16.4 \mathrm{~kJ} / \mathrm{kg}$. Abdewi et al. [75] studied composite tubes of circular cross section (CCS) and radial corrugated cross section (RCCT), and concluded that circular cross section had lower peak loads and lower specific energy absorption compared with corrugated tubes. However, circular composite tubes with inner radial corrugated (RCSCT) did not succeed to show any improvement in load carrying capacity [76].

Mahdi et al. investigated structures of glass/epoxy composite, and the elliptical ratio effect on the normalised SEA, $E_{N s}$ [55]. SEA equation was divided by cross-sectional area of the elliptical area to modify $E_{N s}$. It was concluded that compared to circular tubes, ellipticity ratio of 2.0 has higher $E_{N s}$ and an increase of ellipticity ratio results into higher $E_{N s}$.

Mahdi [77] also studied four different GFRP tubes with various cross-section properties under quasi-static crushing. The specimens included circular cross section, fuselage-shaped cross section and circular cross section with radial-geometrical reinforcement. The author concluded from the results that tubes with radial reinforcements had the highest values for peak load and an average crushing load, crush-load efficiency, absorbed energy, and specific-absorbed energy in comparison to other geometrical shapes.

In study of geometry, Mahdi et al. [78] studied conical shell angles effect on the crushing capability. It was concluded that better energy absorption on SEA of cylindrical structure with $\mathrm{E}_{\mathrm{s}}$ value of $24 \mathrm{~kJ} / \mathrm{kg}$. Furthermore an increase in cone vertex angle results into decrease of SEA, peak load $\left(\mathrm{P}_{\mathrm{L}}\right)$ and volume reduction $\left(V_{R}\right)$. Alkateb et al. [79] states that crushing behaviour was under influence of vertex angle within elliptical cone design. In more details, in elliptical cone vertex angle of $12^{\circ}$, an increase in vertex angle decreases crushing load. Energy absorption improved with increase in vertex angle.

Libo Yan [80] studied crashworthiness characteristics of natural flax fabric reinforced epoxy composite tubes under quasi-static uniaxial compressive load. The author concluded that short length and large number of composite plies results into large value of peak load and CFE. Increase in number of plies for specimens with the same inner diameter and length also increases crushing energy absorption capability significantly. Energy absorption capability of flax/epoxy composite tube is dependent on geometry of the tube and the performance of composite tubes is superior to conventional metal energy absorbers.

Elfetori et al. [81] studied the effect of radial corrugation geometry on the crushing behaviour and energy absorption of circular composite tubes under quasi-static axial compression. The author based on experimental results concluded that structural geometry influences the crushing behaviour and also radial corrugation geometry im- 
proves sliding mode of the structure. Radial corrugation geometry of circular composite tubes also improves energy absorption capability.

Perowansa [82] studied FRP pultruded composite square tubes under axial or oblique impact load. The author concluded that higher impact angle causes lower energy absorption capability. The impact angle and eccentricity of impact load plays an important role in determining the energy absorption capacity.

Palanivelu et al. [45] studied different geometrical structures, mainly on conical circular (CC) type made of glass fibre reinforced polyester composites shown in Figure 2. It was concluded from the work that HG-A and HG-B showed higher SEA value of 21.1 $\mathrm{kJ} / \mathrm{kg}$ and $22.5 \mathrm{~kJ} / \mathrm{kg}$, respectively compared to HG-Y and HG-X that had SEA values of $13.0 \mathrm{~kJ} / \mathrm{kg}$ and $6.96 \mathrm{~kJ} / \mathrm{kg}$, respectively. The failure mechanisms of HG-X and HG-Y were not catastrophic but due to lack of circumferential delamination. Palanivelu et al. [17] [18] studied conical circular geometry of CC-Y and CC-X, and concluded that CC-X showed lower SEA compared with energy absorption value of $23.5 \mathrm{~kJ} / \mathrm{kg}$, and $28.8 \mathrm{~kJ} / \mathrm{kg}$, respectively.

Mahdi et al. studied similar cone-tube-cone composite structure to HG-A [83]. It was stated by the author that specific energy absorption was under influence of tubular part height where normalised tubular height and high SEA value was shown in height/ total height ratio between 0.06 and 0.11 . In another study by the author HG-B cone-cone intersection composite with different vertex angle was studied [84]. It was concluded that more energy absorption was obtained from vertex angle of $20^{\circ}$ and $25^{\circ}$ compared to $10^{\circ}$ and $15^{\circ}$ vertex angle. In carbon and glass fibre comparison it is shown that using fibre as reinforcement enhances energy absorption capability due to enhancement in materials properties. Both materials showed similar trend in material behaviour, increasing vertex angle results into increase of SEA and crushing load.

In summary circular shapes geometry have outstanding performance compared to other geometry shapes tested. Moreover, compared to other shapes apart from radial corrugated circular, circular shapes geometry absorbs most of axial crushing energy. In studies of geometry, highest resistance in the event of crushing was obtained from structure body parallel to the applied load. Lastly in axial crushing, increase of structure angle in any part of structural body affects the SEA.

Farley [74] conducted a study of the influence of specimen geometry on the energy absorption capability and scalability of composite materials by static crushing tests on

(a)

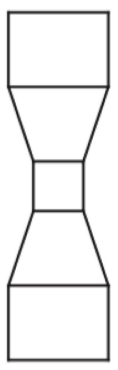

HG-A (b)

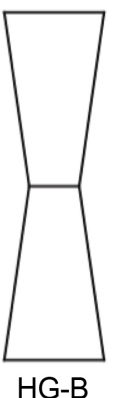

(c)

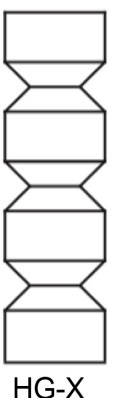

(d)

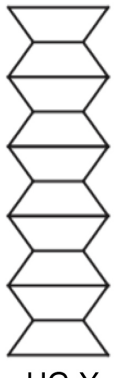

(e)

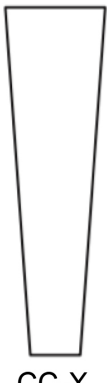

(f)

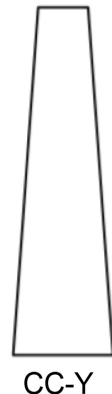

Figure 2. Types of hourglass (HG) and conical circular [44]. 
graphite/epoxy and Kevlar/epoxy square cross section tubes. Czaplicki et al. [85] reported that significantly higher energy absorption of tulip-triggered specimens were observed compared to bevel triggered specimens of the same geometry and material. An external bevel or chamfer ground into one end of the specimen is one of the most common types of crush initiators [86]. Various types of crush initiator are shown in Figure 3.

\subsection{Trigger Mechanism}

Triggering is a process that initiates failure, and avoids load transfer to the whole structure by formation of stress concentration on edges of the profile geometry. Triggering mechanisms therefore prevent composite structures from crushing catastrophically. A suitable selection of triggering helps with progressive crushing so the crush load is at maximum and the load is at a relevant constant value due to various fracture mechanisms such as splaying, fracture modes, etc.

Few studies [34]-[40] [46] stated that more energy was obtained by fibre orientation along the axis of the tube compared to other orientations. Other researchers studied the performance of composite structures based on the effect of $t / D$ ratio and size [87] [88]. The conclusions of these studies were that the overall energy absorption capability of composite tubes determined by the fracture mechanisms that influenced by structure dimensions. To maximise energy absorption and decelerate crushing process, all the composite tubes during impact should exhibit axial cracking, fibre fracturing modes, delamination and bending [24]. Many researchers [23] [25] [26] [34] [89] [90] studied edge chamfering and "I" sectional tubes to investigate its effects on the energy absorption capabilities [31] [36].

Jimenez et al. [53] investigated the effect of triggered composites profile on energy absorption capabilities. Composite tubular type-B with triggering angles of $30^{\circ}$ and $60^{\circ}$ (see Figure 4) reported to perform $25 \%$ deference in level of specific energy absorption. Type-B at $60^{\circ}$ showed a peak load value of $74.7 \mathrm{kN}$ which is the highest. Other investigations were reported on the effect of triggering of different cross-sectional shapes. It is reported that under quasi-static axial crushing the peak load is at maximum with edge triggering at $45^{\circ}$ compared to $90^{\circ}$ tulip triggering [45]. However, tulip triggering showed higher specific energy absorption for all cross section tubes tested than edge
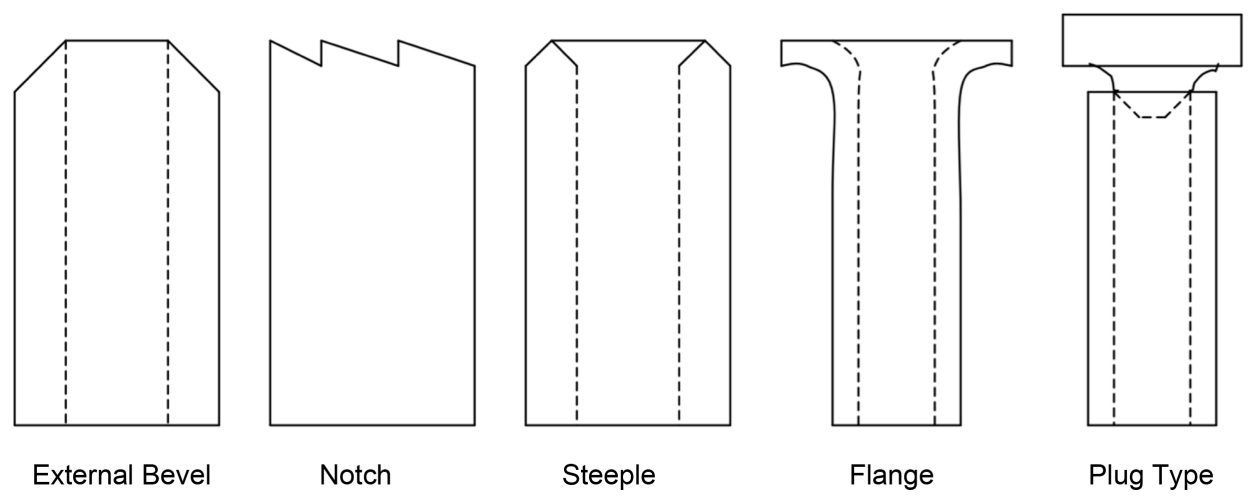

Figure 3. Various types of trigger mechanism [70]. 


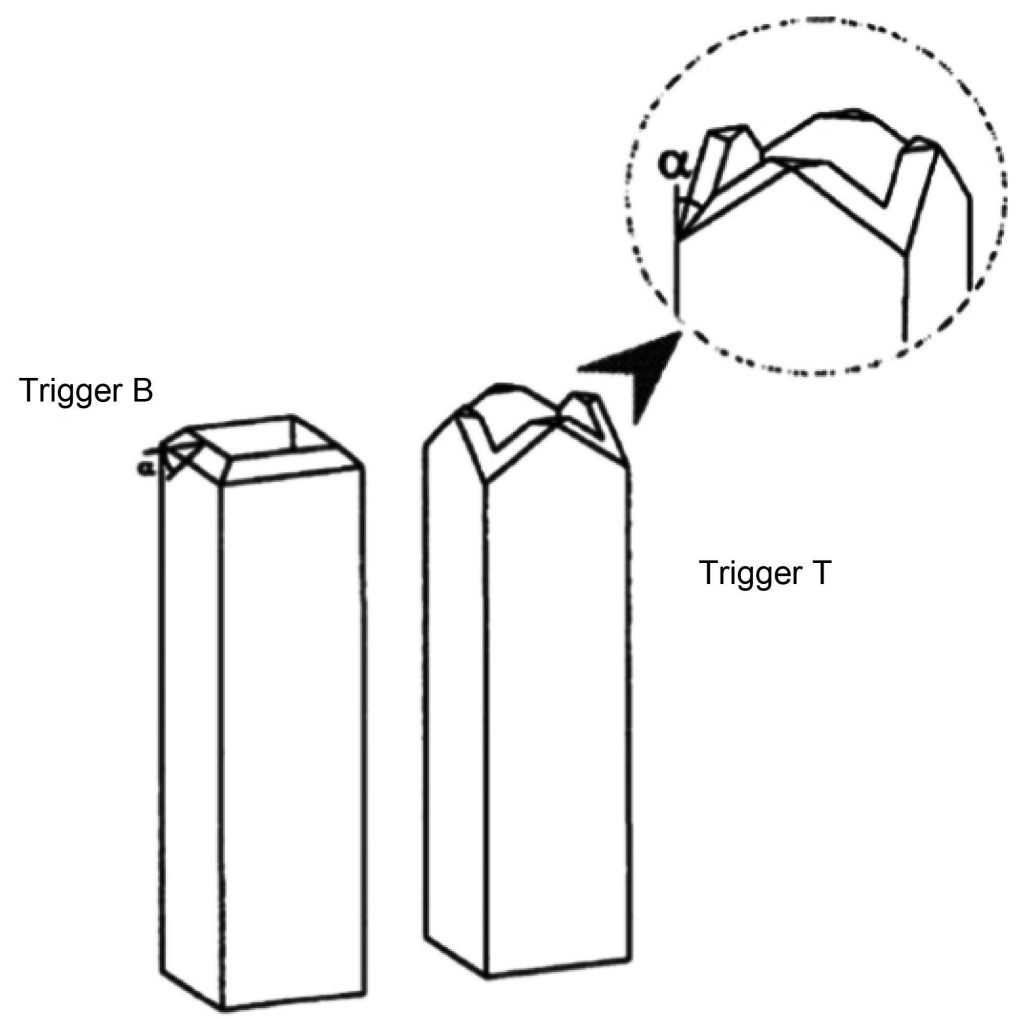

Box section profile

Figure 4. Types of triggering [53].

triggered. Palanivelu et al. [91] investigated the effect of edge trigger and tulip type triggering for round shape on specific energy absorption, and reported an increase of $7 \%$ - 9\% with edge trigger. However, opposite reaction was observed from square shapes. Tulip type triggering showed higher specific energy absorption of an increase of $16.5 \%$. Energy absorption analysis on triggered effect was carried out using carbon and glass hybrid and non-hybrid composite braided rod [92]. It was concluded that progressive crushing was observed from conical triggered rod compared to non-tapered rod that leads to axial crack.

\subsection{Strain Rate Sensitivity}

Extensive work of many researchers has been studied to investigate the influence of strain rate on energy absorption of composite thin-walled structures. Farley [93] reported that matrix stiffness and failure strain are a function of strain-rate and the energy absorption of interlaminar crack growth (delamination) may be considered as a function of crushing speed. Later Farley reported that in $[0 / \pm \theta]_{2}$ carbon-epoxy tubes the energy absorption was not a function of crushing speed, and also found that the energy absorption in $[ \pm \theta]_{3}$ carbon-epoxy specimen is a weak function of crushing speed with an over the speed range tested, which resulted into an increase in energy absorption of around 35\%. Mamalis et al. [21] showed that the strain-rate effects the friction mechanisms developed between crushing surface and different new surfaces created after interlaminar crack growth. 


\subsubsection{Low Impact Velocity}

FRP composite have mechanical property of orthotropic that results into complex damage modes including delamination and microbuckling. FRP composite have complicated with multiple forms of damage mechanisms. At different stages of impact matrix cracking, delamination and fibre breakage can occur and one or more being dominant [94].

In case of low velocity impact according to Cantwell and Morton [95] either of striking velocity that referred to velocities up to $10 \mathrm{~m} / \mathrm{s}$ reconstructed by testing a falling weight impact, and according to Abrate [96] impact velocity test of less than $100 \mathrm{~m} / \mathrm{s}$ or as suggested by Liu and Malvern [97] the extent of damage on the material that arise from different sources including drops, foreign object hits, hailstone impact, maintenance and in-service impacts. In metallic materials the stress induced from low velocity impact due to ductile nature and high potential of energy absorption may not be considered threatening. However, in composite materials at micro-scale level, low velocity impact may induce significant damages, resulting into reduction of strength and stiffness of the material [96] [98]-[106].

Extensive research of FRP composites has been conducted at low velocity impact damage to study further the complex nature of damage mechanisms. Both properties of impactor and impacted material which influence the impact loading in FRP composites and could result into different failure modes [107] [108]. Composite materials subjected to low velocity impact encounter failure modes of matrix mode, delamination mode, fibre mode and penetration [109]. Incipient impact energy, Fibre/matrix configuration, composite laminate thickness, impact velocity and impactor shape are essential parameters towards different types of failure modes. In composite materials, the interaction between failure modes affect energy dissipation properties and damage progress.

Low velocity impact in composite material has two critical threshold forces, Hertzian failure load and maximum impact load, with two critical threshold energies, penetration energy and perforation energy. Initial sign of significant damage in laminated composites subjected to low velocity impact is delamination. Delamination failure is categorised as damage threshold known as Hertzian failure force [110] [111]. Delamination failure occurrence is due to lack of fibres contribution to overall strength within the thickness direction whist subjected to out of plane stresses generated by impact loading. At the interfaces delamination transpire between plies that debonds individual laminas due to bending deformations of adjacent plies differences.

Fibre fracture and laminate failure modes, which are the main damage mechanisms occur whist reaching maximum force threshold and develops up until maximum energy level is reached [110] [112] [113]. However, at low impact energy, matrix cracking occur although it does not degrade the mechanical properties, delaminations significantly affect the laminates performance. Fibre damage, additionally, result laminate failure (main failure) in laminates of composites.

Shyr and Pan [110] studied the effect of low velocity impact damage characteristics on various reinforced fabric structures with different laminate thicknesses. The study signifies number of ply layers which determines the energy absorption capability. In thick laminates the dominating failure mode was fibre fracture whereas in thin struc- 
tures delamination is more influential. The author concluded that the major threshold load damage was independent to incipient impact energy, but dependent to laminates thickness. Similar conclusions were reached and stated by Belingardi and Vadori [112].

Yang and Cantwel [114] investigated experimentally the effect of varying key impact parameters on the damage initiation threshold of temperatures of $23^{\circ} \mathrm{C}$ to $90^{\circ} \mathrm{C}$ at low velocity impact tests on $\left(0^{\circ}, 90^{\circ}\right)$ glass/epoxy laminated composites. The authors concluded that initial threshold damage showed a $t 3 / 2$ dependency, where $t$ is thickness of the laminate, at both room and elevated temperatures.

Energy thresholds of penetration and perforation, which are among the main characteristic properties subjected to low velocity impact in FRP composites can be determined using energy profiling technique. A correlation between characteristic impact properties and major failure modes can be developed using energy profiling technique [115]. Quaresimin et al. [116] studied the effects of laminate thickness and stacking sequence on energy absorption capability under low velocity impact using woven carbon-epoxy composite laminates. The authors concluded that threshold energy and delamination threshold load for initial failure are inconsiderate to laminate lay-up and impact energy. Whereas laminate lay-up showed to be quite independent by maximum contact force which increases slightly with impact energy.

\subsubsection{Loading Conditions}

In engineering applications generally, the loading classification are static, fatigue, high speed/rapid loading and impact. These loads are categorised according to the rise time of the load. For static loading this time is 3 times greater than the fundamental period of the mechanical system. Fatigue loading occurs when rise time from one magnitude to another magnitude is greater than 3 times of fundamental periods. This time for high speed loading is between 1.5 to 3 times the fundamental periods of the mechanical system. The rise time for impact loading is less than half times the fundamental period of the mechanical system. Impact is an important area of applied mechanics, which is strongly related to engineering practice, such as structural engineering, manufacturing engineering, aerospace engineering and material engineering. The application of impact is endless and has resulted in significant achievements both technically and economically [117] [118] [119].

For a period of short time the impact process involves relatively high contact forces acting over a small area. At the point of contact of two solids, local strains generated that results into energy absorption [86]. The impact event may result in damage if energy absorption exceeds a threshold. A laminated composite facing a projectile strike, results into fracture processes involving delamination, matrix crack and fibre fracture. Impact is defined for studying of force acting locally as a resulting of the impact event. Contact law relates a connection between the contact force and the indentation, which can be interpreted into the difference between the displacement of the projectile and the back face of the laminate.

The initial response of impact loading is to cause damage near the surface of the laminate. Although the inner layers of the composite are damaged as well and the material stiffness changes locally as the projectile penetrate into the laminate [120]. In the 
duration of the impact event it cannot be assumed that the contact force to be constant [121] [122]. Furthermore, different projectile geometries were employed in order to reproduce real loading situation to measure the modifications of the composite reaction [123].

In quasi-static model testing, the impact response is a function of time dependant and the composite model is expressed as a time dependent force that is represented by an equivalent mass with equivalent stiffness [124] [125]. All forms of damage should be studied and considered due to the likelihood of the influence of the material residual mechanical properties, from each damage form.

\section{Collapse Modes and Failure Mechanisms}

Three main modes of brittle collapse are categorised as mode I, II and III which were studied on square tubes in the series of static and dynamic axial compression tests, respectively [126]. According to Hull classification [17] Euler overall column buckling or progressive folding with hinge formation were not found for fibre-reinforced plastic (FRP) composite tubes. Energy absorption in most fibre-reinforced composites are through a combination of fracture and friction [127]. The two main failure mechanisms of composite tube are catastrophic and progressive failures (see Figure 5). A stable progressive crush is established by localised failure that initiates at one end of the specimen and progress through the specime. To reach this failure mechanism, crush initiator is used for FRP tubes. During catastrophic failure the initial maximum force is very high and drops rapidly, therefore the average force is low.

\subsection{Failure Mechanism}

According to Mamalis et al. [126] in general the failure modes observed are greatly affected by the shell geometry, fibres arrangement, matrix and fibres properties of the composite material and the stacking sequences. Moreover, the macroscopic collapse modes in Figure 6 was classified by Mamalis et al. [126] [127] [128] from various geometries in extensive experimental treatment of axisymmetric tubes made of fibre-reinforced polymer matrix composite materials.

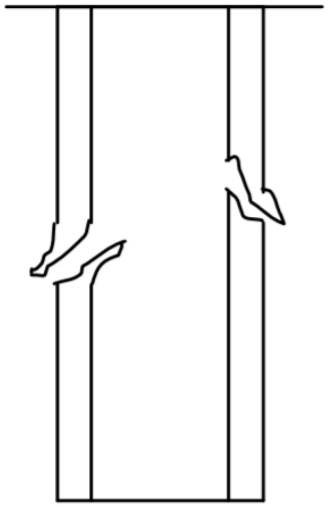

(a)

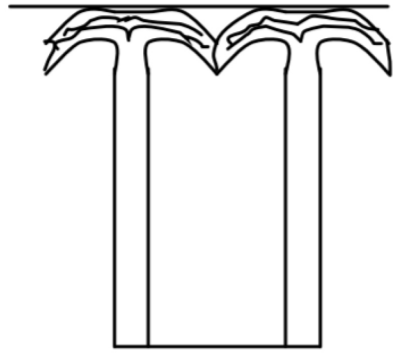

(b)

Figure 5. Typical collapse modes for composite tubes (a) catastrophic failure (b) progressive failure [127]. 


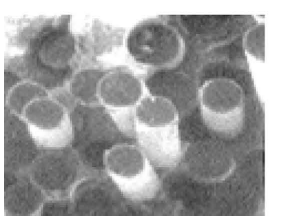

Longitudinal fracture of matrix

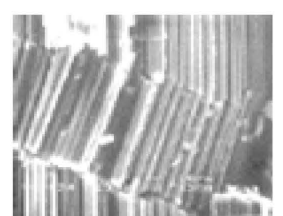

Fibre compressive failure-kink band

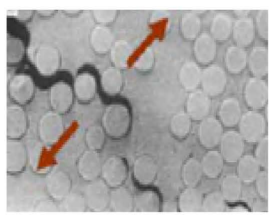

Matrix micro-cracking under transverse tension

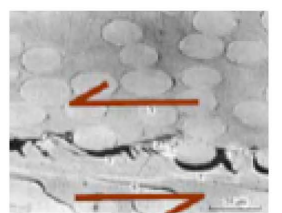

Fibre/matrix debonding under shearing

(a)

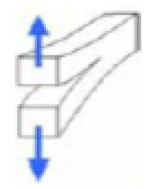

Delamination in Mode-I

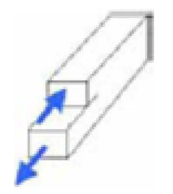

Delamination in Mode-II

(b)

b)

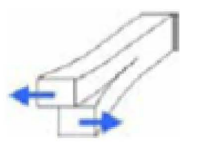

Delamination in Mode-III

Figure 6. Fracture mechanisms observed in laminates (a) Interalaminar and (b) Interlaminar Failures [129].

\subsubsection{Progressive Failure}

Composite material progressive crushing with micro-fragmentation, associated with high crush energy, is designated as mode-I. Progressive failure mode is classified by the progressive end-crushing with splaying of the laminate tube starting at one end of the specimen. This causes the tube to form continuous fronds which spread outwards and inwards.

\subsubsection{Catastrophic Failure}

The component's brittle fracture with little energy absorption resulting in catastrophic failure is designated either as Mode-II or Mode-III depending on the crack formation. Mode-II is classified by a spiral or longitudinal crack propagation developed along the shell circumference. Mode-III is classified by the circumferential fracturing formation of the specimens approximately equal to the mid-height of the shell into irregular shapes, and described as mid-length collapse mode.

\subsection{Progressive Folding}

Similarly, to crushing behaviour of thin-walled metal and plastic tubes, progressive folding and hinging have a very low energy absorbing capacity, which is introduced as Mode-IV. Mamalis et al. [48] [49] reported that the collapse modes can be categorised into two groups of stable and unstable collapse modes. Stable collapse modes have similar features as static loading whilst at the same geometries. According to Mamalis et al. [126] in some applications a failure could be considered by a very small deformation, and in others a total fracture or separation constitutes failure. In composite materials generally, the internal material failure initiates before any alteration in macroscopic appearance or behaviour. This indicates that failure takes place before any indication in macroscopic molecules.

Various fracture modes can be defined for a laminate composite. These modes are 
divided into intralaminar and interlaminar fracture modes. Intralaminar mode consists of longitudinal matrix fracture, transverse matrix fracture, fibre-matrix debonding and fibre fracture. Interlaminar mode is also referred to as delamination. Delamination is described as separation of layers from one another (see Figure 6). The fracture mechanisms depend upon the nature of the constituents including architecture of the layers, and mechanical loading mode [129].

Mamalis et al. [21] reported that the main microfracture mechanism features of composite tubes are similar to that obtained for circular tubes. These microfracture mechanisms are:

- An annular wedge of highly fragmented material, axially forced downwards through the shell wall;

- Ahead of the crush-zone an intrawall microcrack is developed at the apex of the annular wedge with approximately a propagation of the compression rate;

- Plies delamination in the crush zone causes two continuous fronds, mainly developed by the central bundle wedge that radially spreads inwards and outwards from the wall;

- Between the central crack and the shell wall edges a severely strained zone is formed showing a combined tensile-compressive type of deformation.

Farley and Jones [130] named and classified three main crushing modes for progressive failure of composite box in crushing process as follow.

\section{- Transverse shearing}

Fragmentation or transverse shearing mode is characterised by the laminate wedgeshaped cross section with a single or multiple short interlaminar and longitudinal cracks. In this mechanism the energy absorption is controlled by the interlaminar crack propagation and bundle fracture.

\section{- Lamina bending}

Lamina bending mode is parallel to fibre cracks shaped with long interlaminar, intralaminar. This mechanism initiates the formation of inwards and outwards spreads of continuous fronds. The energy absorption of lamina bending mode is controlled by inter/intra laminar fracture and friction. However, the fragmentation and lamina bending modes combination is known as brittle fracture mode. In composite tubes the highest energy absorption ever observed is from the combination of brittle fracture and lamina bending crushing mode.

\section{- Local buckling}

The local buckling crushing mode involves local buckle formation meaning plastic deformation of the material. The result of ductile fibre-reinforced composites integrity in post crushing is from fibre and matrix plasticity without any fracture and fibre splitting. Local buckling can exhibit from brittle fibre-reinforced composites when small interlaminar stresses relative to the strength of the matrix, or the matrix has a higher failure strain than the fibre, and when plastic deformation under high stress exhibited from the matrix.

Brittle fibre-reinforced composites exhibit the transverse shearing and lamina bending crushing modes, although ductile fibre-reinforced composite materials have similar mode behaviour as ductile metals in local buckling crushing see Figure 7. 

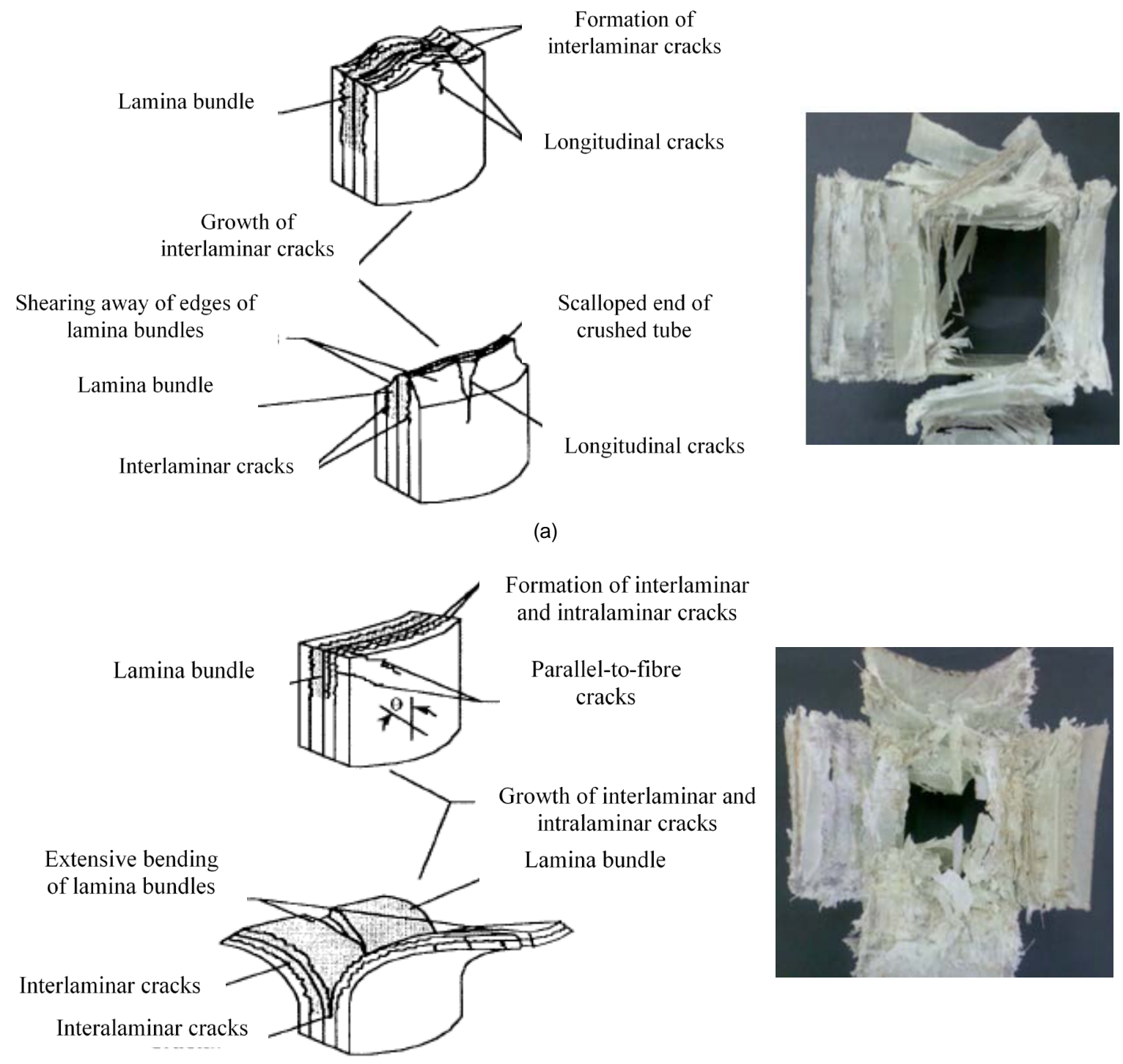

(b)

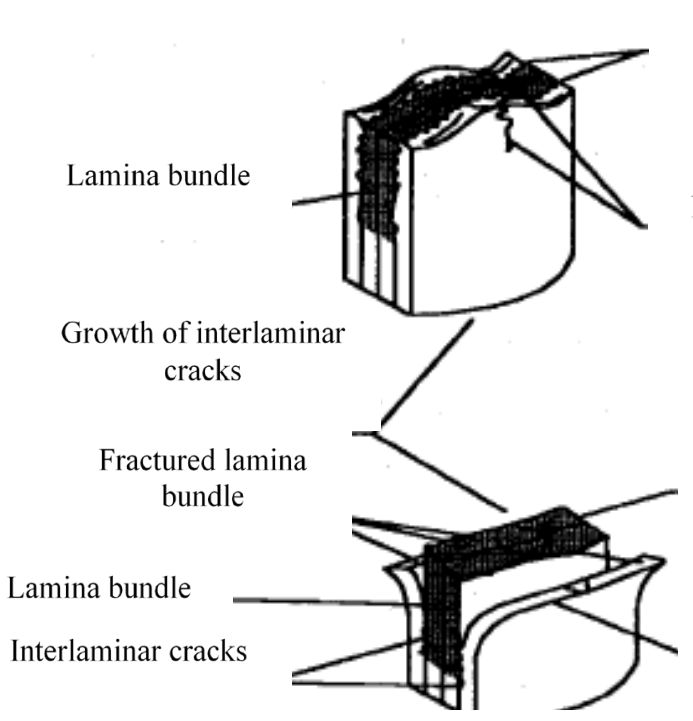

Formation of interlaminar cracks

Scalloped end of crushed tube

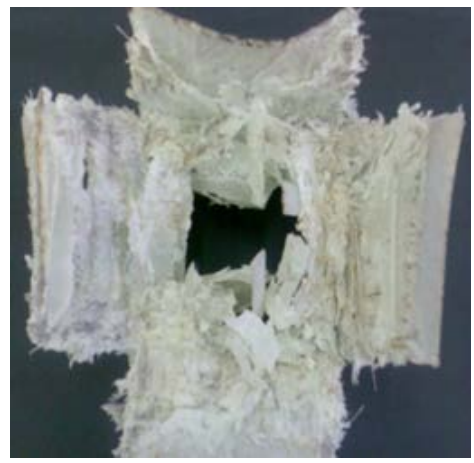

Longitudinal cracks

Bending of lamina bundles

(c) 

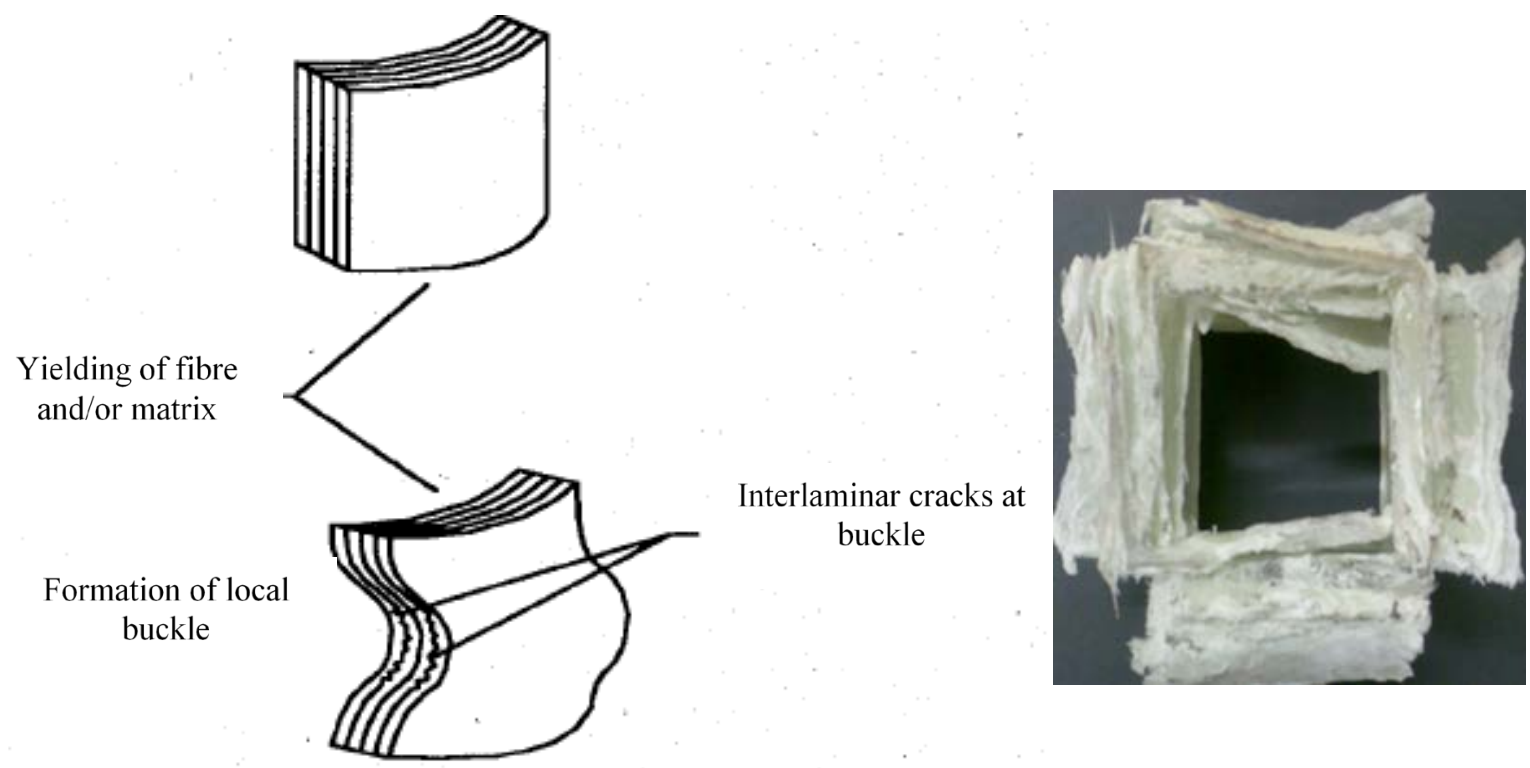

(d)

Figure 7. (a) Transverse shearing crushing mode, (b) Lamina bending crushing mode, (c) Brittle fracture crushing mode, (d) Local buckling crushing mode [131].

\section{Theoretical Prediction of Crushing Energy}

Various theoretical approaches have been proposed to study static axial collapse energy absorption of composite multi-layered shells. Farley and Jones [130] proposed the following simplified phenomena to encounter the crushing process:

- Friction between the fronds and annular wedge, and between the platen of the press and fronds.

- Fronds bending,

- Crack propagation.

- Axial splitting.

Mamalis et al. [132] introduced another composite circular tubes analysis subjected to static axial compression, which has been modified and used on analysis of collapse mechanism. Using this model, the estimation of the related energy absorption subjected to axial crushing of square tubes is obtained. According to Mamalis et al. [133], during the elastic deformation of the shell, the load rises at a steady rate to a peak value, $F_{\max }$. The cracks formed at four corners of the tube in length, $L_{c}$, propagate downwards along the tube axis causing the shell wall to split (see Figure 8), accompanied by circumferential central intrawall crack development at the top end of the shell. It is assumed that the crack follows an ellipsis configuration. At the middle of each side of the square cross section the maximum value of the crack length, $L_{c}$, is attained, and is an equal correspondence to equivalent circular tube loaded under the same condition. Therefore, the energy absorption of associated part, which is equivalent to external work, can be obtained by measuring the area within the elastic regime under the forcecrush distance curve,

$$
U_{L C}=2\left[\pi \cdot L_{C} \cdot\left(\frac{b}{2}\right)\right] \cdot R_{a d}+n\left(\frac{t}{2}\right) G \cdot L_{C}=\frac{1}{2} F_{\max } \cdot S_{1}
$$




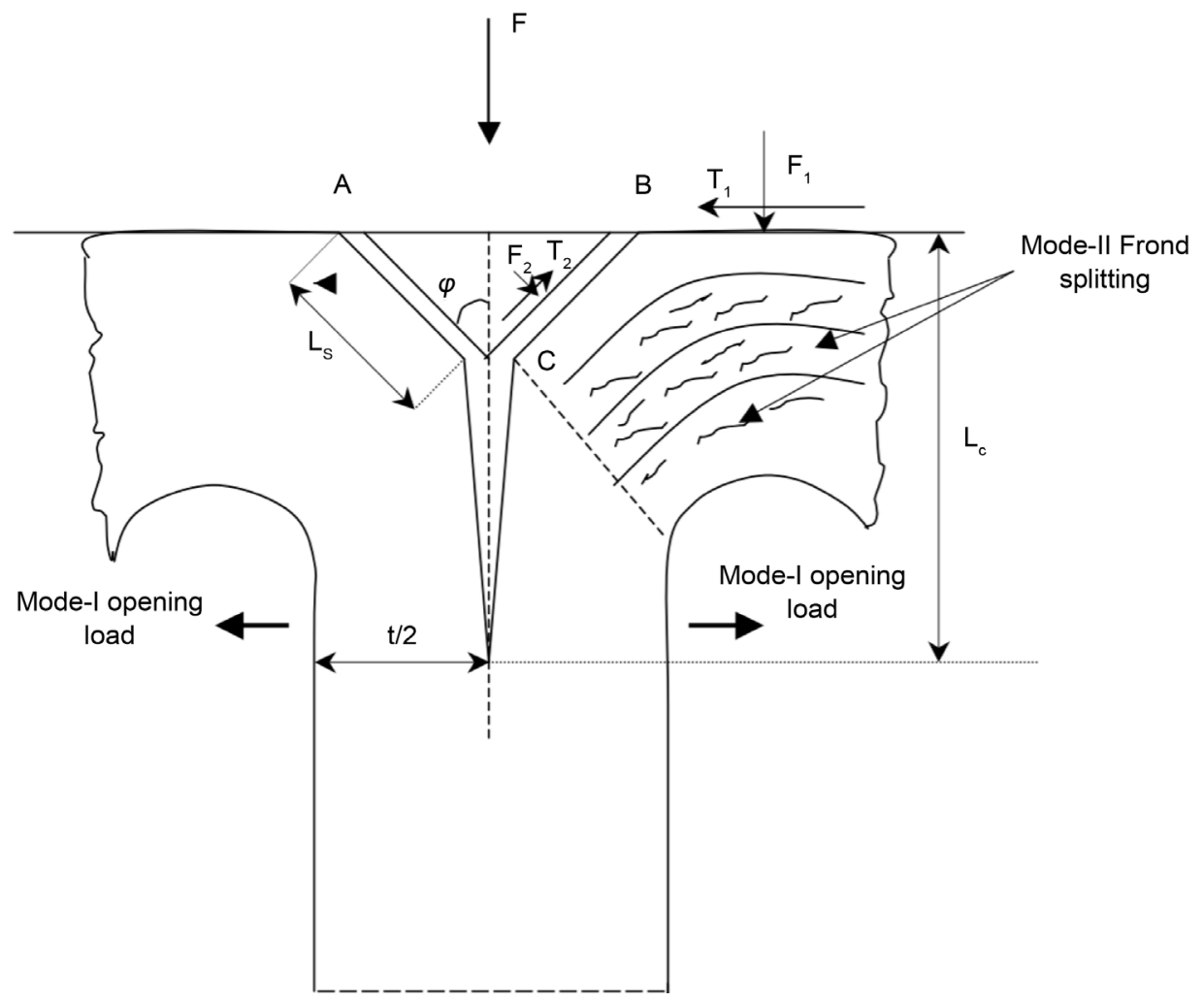

Figure 8. Configuration of the crush zone in the middle of the tube side [133].

where $R_{a d}$ notation is the fracture energy required for a unite area of adhesive to get fractured at the interface between two adjacent layers, obtained by fracture theory,

$b=$ Tube side width,

$n=$ Number of layers,

$t=$ Shell wall thickness,

$G$ = Fracture toughness,

$S_{1}=$ Elastic crush distance.

The amount of energy required for the deformation mechanism in reference to the history of the formation of the crush zone, is equal to the deforming shell in this regime absorption of external work (see Figure 8),

$$
U_{t r}=\left[2 \int_{0}^{\varphi} \sigma_{0} \cdot l_{s}\left(\frac{l_{s}}{2}\right) \mathrm{d} \theta\right] 4 b=\int_{s_{2}}^{s_{1}} F \cdot \mathrm{d} s
$$

where

$\sigma_{0}=$ The normal stress applied by the wedge to frond,

$l_{s}=$ The side length of the wedge inscribed to the bent fronds,

$\varphi=$ The semi-angle of the wedge,

$s_{2}=$ The related shell shortening corresponding to the completion of the wedge formation.

The total dissipated energy for a crush distance due to friction between the annular wedge and fronds, and between fronds and platen can be written as:

$$
U_{1}=2\left(F_{1} \cdot \mu_{S_{1}}+F_{2} \cdot \mu_{S_{2}}\right)(4 b)\left(S-S_{1}\right)
$$


where $F_{1}$ is the normal force per unit length applied by the platen to the internal and external frond, $F$ is the normal force per unit length applied to the sides of the wedge, $s$ is the total crush distance, $\mu_{s_{1}}$ is the coefficient of friction between frond and platen and $\mu_{S_{2}}$ is the coefficient of friction between the wedge and the fronds. $F_{2}$ and $\sigma_{0}$ are equal to,

$$
F_{2}=\sigma_{0} l_{S}
$$

And

$$
\sigma_{0}=k \cdot \sigma_{u}
$$

where $k$ is a constant and $\sigma_{u}$ is the ultimate tensile stress of the composite material.

Other energy dissipated due to fronds bending, crack propagation, and axial splitting are;

$$
\begin{gathered}
U_{2}=2\left[\int_{0}^{\varphi}\left(F_{2}\right)\left(\frac{l_{s}}{2}\right) \mathrm{d} \theta+\int_{S_{2}}^{S_{1}}\left(F_{2}\right) \cdot \theta \cdot \mathrm{d} s\right] 4 b \\
U_{3}=G_{I C}\left[4 b\left(S-S_{1}\right)+\pi \cdot L_{C} \cdot b\right] \\
U_{4}=4\left(\frac{t}{2}\right) \cdot G_{1} \cdot S \\
G_{1}=\frac{k^{2}}{E} .
\end{gathered}
$$

From Equations (3), (6), (7) and (8), the total energy dissipated for the deformation of the shell is obtained as,

$$
U_{1}=U_{1}+U_{2}+U_{3}+U_{4} .
$$

Therefore, the total force applied by the platen to the shell can be calculated as,

$$
F_{m}=\frac{U_{\text {cocal }}}{s} .
$$

\section{Off-Axis Crashworthy Behavior of FRP Composite Box Structures}

Although most study concentration of previous works have been on crushing under axial loading. In a real life crashing event scenario the likelihood of having a non-axial collision is very high. Quite recently few researches have concentrated on the energy absorption capabilities of elements such as box under two types of non-axial loadings. Non-axial loadings are also known as off-axis loading and angled loading. Occurrence of off-axis loading is when the impact of an object is from a direction not along its longitudinal axis. Occurrence of angled loading is when the impact of an object is from being perpendicular to longitudinal axis. It is essential to undertake all of the effects of collision in crashworthy composite structures on the capabilities of energy absorption. In off-axis crushing the formation of fracture mechanisms defer from axial crushing observations. During non-axial progressive collapse, an important role in dissipation of crushing energy is non-symmetrical crack propagation at the interwall box and between fronds.

Few researchers have been investigating the effects of off-axis crushing on the energy 
absorption of composite materials and structures [133] [134] [135]. Czaplicki et al. [133] investigated on off-axis loading and angled loading crushing process of E-glass/polyester pultruded tubes. It was concluded that off-axis loading and angled loading conditions dissipate energy in different friction mechanism but both loading conditions observed a similar energy absorption tendency by increasing the inclination angle. It was also concluded that at $10^{\circ}$ off-axis angle the mean crushing force increases in comparison to mean crushing force of axial crushing and a steady decrease with increase of angle of inclination. Song and Du [134] studied the energy absorption capabilities of offaxis loading of glass/epoxy and glass/polyester composite tube laminated from various lay-ups. Three characteristic crushing stages were identified according to their extensive research, triggering stage ( $\mathrm{Tr}$ ), sustained crushing stage and toppling stage. In general, as the off-axis inclination angle increases the energy absorption decreases, caused by a change in two factors of toppling tendency and fracture pattern. They also concluded that $0^{\circ}$ ply can prevent the circumferential cracks and therefore longitudinal resistance to delay the toppling stage (see Figure 9 and Figure 10).

Ochelski and Gotowicki [135] conducted experiments on the effect of fibre reinforcement type, structure type, fibres orientation in a layer and layers stacking sequence on the energy absorption capabilities of tubes and truncated cones. Also carried out analysis on the effect of the specimen's thickness and applied loading direction on the specific energy absorption (SEA).

\section{Interlaminar Fracture Toughness}

The energy absorption from interlaminar fracture toughness is accompanied by various fracture mechanisms of intralaminar and interlaminar. In study of fracture toughness, delamination growth is one of the most important areas to concentrate on the study of energy absorption capability of composite structures. Progressive failure mode and

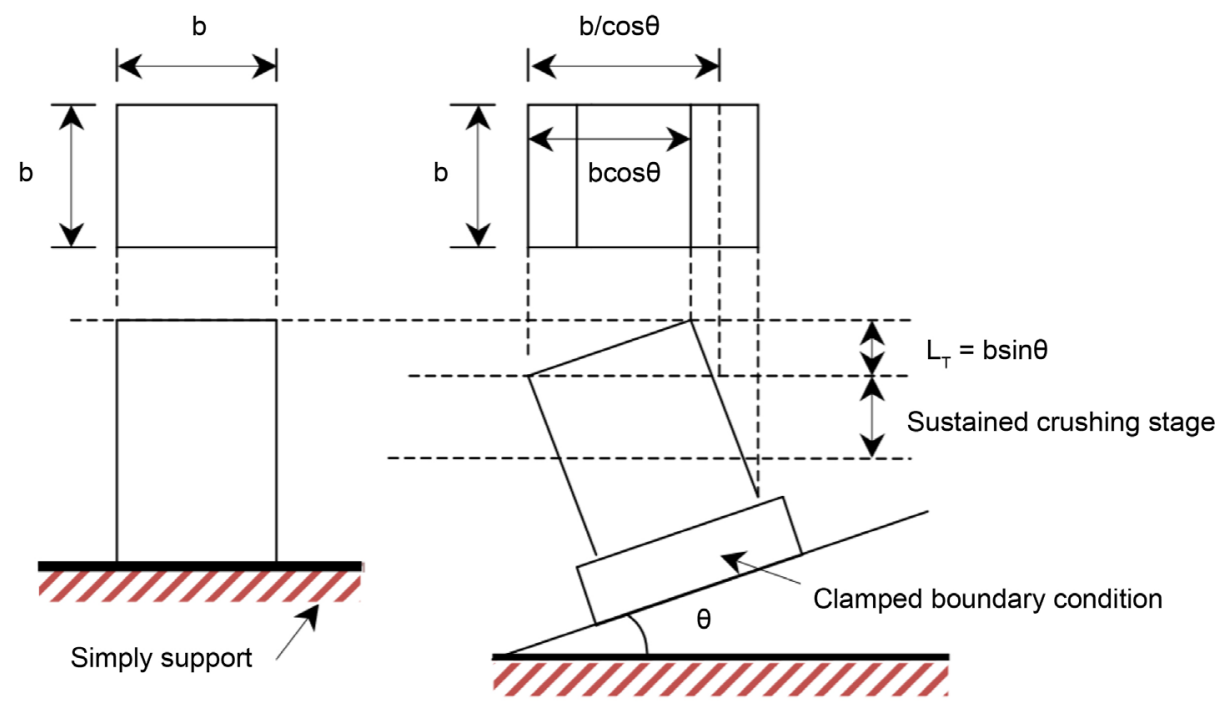

(a)

(b)

Figure 9. Comparison of axial and off-axis crushing process, (a) axial crushing and (b) off-axis crushing [143]. 


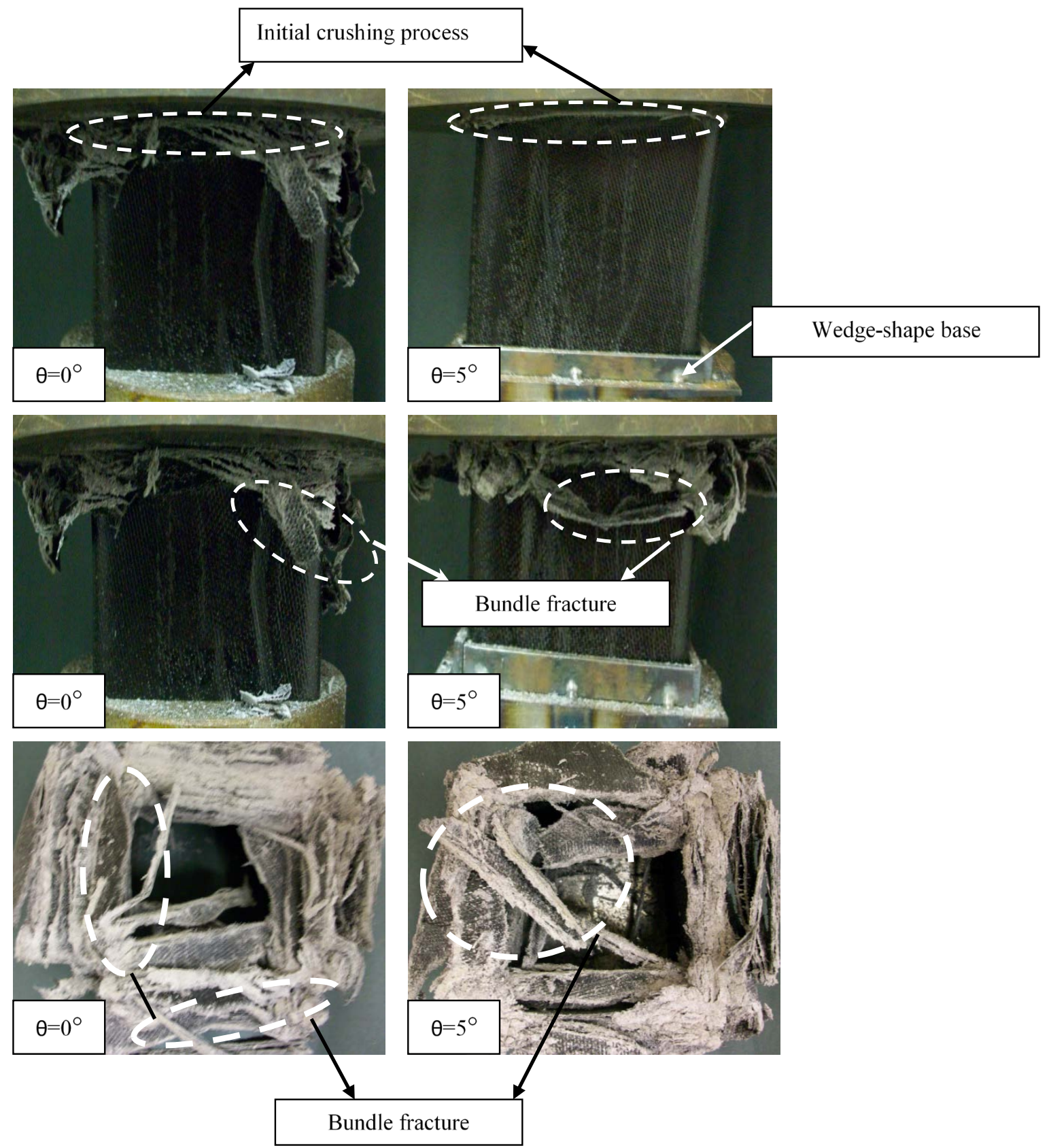

Figure 10. Various crushing stages of woven glass/epoxy composite box in axial crushing $(\theta=0)$ and off-axis loading at $\left(\theta=5^{\circ}\right)[143]$.

energy absorption of composite structures, are effected mainly by various fracture mechanisms including fibre breakage and buckling, matrix cracking and crushing, debonding at the fibre-matrix interface and especially plies delamination. Shear and tensile separation between fronds cause delamination. Energy absorption is the effect of these two crushing mechanisms that are due to interlaminar and intralaminar crack growth and fracturing of lamina bundles. The sources of energy absorption during progressive collapse are mainly from [136]:

- Frictional resistance between wedge and fronds and between fronds and platen: about $45 \%$ of total absorbed energy. 
- Frond bending due to delamination between plies: about $40 \%$.

- Interwall crack propagation: about $12 \%$.

- Axial splitting between fronds: about 3\%.

Warrior et al. [137] studied the influence of thermoplastic resin additives, toughened resins, stitching through-thickness, thermoplastic interleaving on the interlaminar fracture toughness $\left(G_{I C}\right)$, SEA for continuous filament random mat (CoFRM) and 0/90 non-crimp fabric (NCF) E-glass reinforced polyester composite tubes. It was concluded that the above factors increase $G_{I O}$ but toughened resin and through-thickness stitching affect increase in SEA. In general a tougher matrix result into a higher $G_{I C}$ in composites, this is beneficial in crashworthiness design [138]. Cauchi Savona et al. [139] studied the relation of glass fibre reinforced plastic composite plates between sustained crushing stress with their Mode-I and Mode-II fracture toughness properties. It was concluded that materials with low Mode-I and Mode-II fracture toughness, yield low crushing energies. Solaimurugan et al. [140] [141] studied the effect of stitching, fibres orientation and stacking sequence on $G_{I O}$ SEA, and progressively crushing of glass/ polyester composite cylindrical shells under axial compression. It was concluded that placing axial fibres close to outer surface tube cause formation of more petal and stable crushing process, whereas placing axial fibres close to inner surface tube led to higher energy absorption. Moreover, circumferential delamination increases energy absorption for higher values of Mode-I fracture toughness. Also reported stitching causes higher energy absorption of cylindrical tube due to increase in Mode-I interlaminar fracture toughness.

Ghasemnejad et al. [142] studied the energy absorption of GFRP composite box affected by Mode-I interlaminar fracture toughness. It was concluded that during progressive collapse, a significant amount of energy absorption is attained by frond bending following the growth of a main central inter-wall crack due to delamination in the sidewall. The main central inter-wall cracks are Mode-I interlaminar crack propagation. Also concluded that engineering the laminate design for composite box improves energy absorption capability due to improving interlaminar fracture toughness. For different lay-ups the variation of specific energy absorption (SEA) with interlaminar fracture toughness is non-linear.

Hadavinia and Ghasemnejad [57] investigated the energy absorption of laminated CFRP composite box by the effect of Mode-I and Mode-II interlaminar fracture toughness. In combination of lamina bending/brittle fracture crushing mode according to their results, crack propagation development in Mode-I and Mode-II causes higher crushing energy absorption relative to combination of local buckling/transverse shearing crushing mode that consists of only Mode-II interlaminar crack propagation. Ghasemnejad and Hadavinia [143] studied the off-axis crashworthy behaviour of woven GFRP composite box structures. They concluded that two fracture mechanisms of bundle fracture and crack propagation delamination in Mode-II for all composite boxes at various off-axis loading was observed. In Mixed-Mode I/II due to crack propagation and more resistance and friction at side of composite box that initially contacted the crushing platen, at off-axis loading of $10^{\circ}$ the amount of SEA was maximum compared to other off-axis crushing load. Ghasemnejad et al. [56] have conducted 
more detailed study of hybrid composite box structures crashworthy behaviour affected by delamination failure. It was concluded that the hybrid laminate designs have higher fracture toughness in Mode-I and Mode-II. Hybrid composite box structure have shown a great increase in energy absorption capabilities in crushing process. Most recently, author [144] studied the effects of delamination failure of stitched composite box structures, where the specimen's crashworthy behaviour and performances were compared and studied against simple non-stitched specimens, under the same geometry and condition. A combination of unidirectional CFRP and GFRP composite materials with lay up of $\left[C_{90} / G_{0}\right]_{7}$ were used to laminate the composite boxes. The laminate design obtained the highest energy absorption capability within the previous study of authors. Delamination study in Mode-I was carried out using the same lay-up to study the effect of crack growth of delamination on energy absorption of natural stitched composite box structures. Using double cantilever beam (DCB) standard test for delamination studies. It was concluded stitching significantly increased interlaminar fracture toughness and consequently energy absorbing capability of composite materials and structures (see Figure 11).

In recent years two techniques have been developed to increase crack propagation resistance and reduce delamination. One is three-dimensional composites constructed from yarns or tows. Authors [141] [142] [143] [144] [145] studied the effect of stitching and stitching pattern on energy absorption capabilities and found an increase of delamination resistance by introducing stitching pattern and increase of SEA. 3D composites include, 3D woven composites, 3D braided composites, 3D stitched composite, 3D

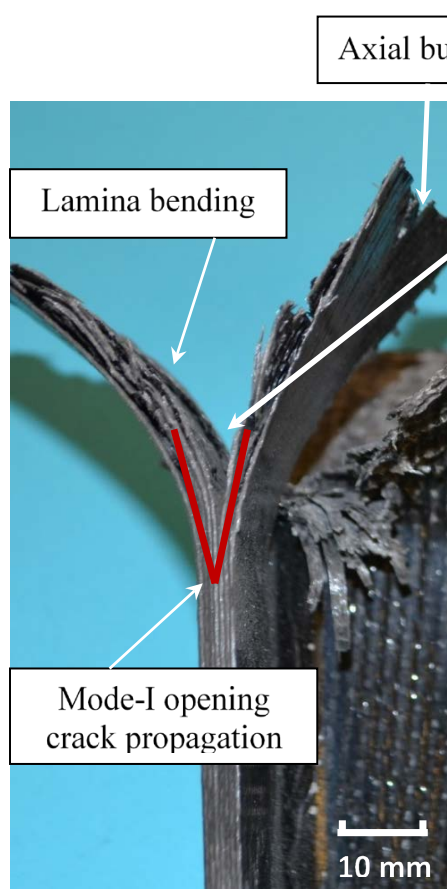

a
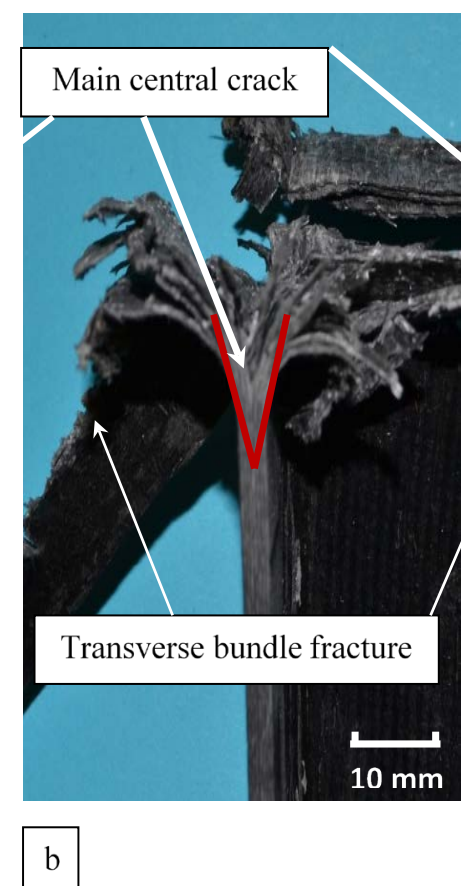
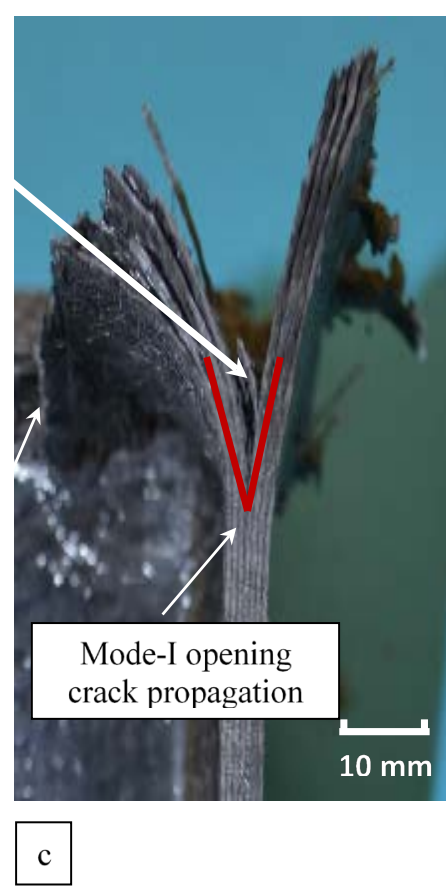

Figure 11. Mode-I interlaminar crack propagation at the central inter-wall, (a) lamina bending crushing mode for non-stitched, brittle fracture mode for (b) stitched-10 $\mathrm{mm}$ and (c) stitched-20 mm composite crush box [144]. 
Table 1. Overview of investigated concepts.

\begin{tabular}{cc}
\hline Crushing factors & References \\
\hline Fibre and matrix type & {$[58]-[66]$} \\
Structrual geometry & {$[21][44][50][55][62][74]-[84]$} \\
Laminate design & {$[60][62][64][67]-[73]$} \\
Strain rate sensetivity & {$[21][93]-[125]$} \\
Theoretical analysis & {$[13][19][21][42][44][45][51]-[57][130]-[133]$} \\
Loading condition & {$[23][25][26][34]-[40][45][46][47][53][58][70][87]-[92]$} \\
Fracture Mechanism & {$[17][21][48]-[58][126][127][128][129][130][136]-[145]$} \\
\hline
\end{tabular}

Z-pinning. All of these have been studied extensively and are still being studied for further improvements. Author [145] for instance developed a novel technique of stitching pattern to increase energy absorption using glass yarn on composite absorber sections without increasing structural weight. This is useful in automotive and aerospace industry.

Another technique is resin based to reinforce the composite structure by increasing the resistance between plies. Three main types of resins are available polyesters, Vinyl ester, epoxy. Altering the chemistry of the resin improves its strength, consequently energy absorption capability is increased. Author [131] states that further analysis of thermosetting resin matrices needs to be carried out to understand its effect on energy absorption capabilities.

Further investigations can be carried out on the effect of stitching on woven composite with resin infusion. This gives the best of the two worlds. No damages are caused on to the woven composite by introducing stitching pattern along with having a well-constructed resin injected to create the final 3D composite structure.

\section{Conclusion}

This paper has extensively reviewed progressive crushing behaviour of FRP composite tubular structures in past two decades. In axial crushing of composite, high-energy absorption was contributed by fracture failure. Two fracture failure types are catastrophic and progressive failure. Catastrophic failure results in minimal energy absorption whereas progressive failure due to multi-failure modes results in high-energy absorption. This paper reviewed the literature in 7 sections as material type, structural geometry, laminated design, strain rate, loading conditions, theoretical analysis, and consequently fracture mechanisms. The details of references included in this work are summarised in Table 1.

\section{References}

[1] DiPaolo, B.P. and Tom, J.G. (2006) A Study on an Axial Crush Configuration Response of Thin Wall, Steel Box Components: The Quasi-Static Experiments. International Journal of Solids and Structures, 43, 7752-7775. https://doi.org/10.1016/j.ijsolstr.2006.03.028

[2] Santosa, S. and Wierzbicki, T. (1998) Crash Behaviour of Box Columns Filled with Aluminium Honeycomb or Foam. Composite Structures, 68, 343-367.

https://doi.org/10.1016/S0045-7949(98)00067-4 
[3] Santosa, S. and Wierzbicki, T. (1999) Effect of an Ultralight Metal Filler on the Bending Collapse Behaviour of Thin Walled Prismatic Columns. International Journal of Mechanical Sciences, 41, 967-993. https://doi.org/10.1016/S0020-7403(98)00066-6

[4] Cheng, Q., Altenhof, W., Jin, S.Y., Powell, C. and Harte, A.M. (2006) Energy Absorption of Aluminium Foam Filled Braided Stainless Steel Tubes under Quasi-Static Tensile Loading Conditions. International Journal of Mechanical Sciences, 48, 1223-1233. https://doi.org/10.1016/j.ijmecsci.2006.06.009

[5] Kotzialis, C., Derdas, C. and Kostopoulos, V. (2005) Blast Behaviour of Plates with Sacrificial Cladding. 5th GRACM International Congress on Computational Mechanics, 29 June-1 July 2005, Limassol.

[6] Guruprasad, S. and Mukherjee, A. (2000) Layered Sacrificial Claddings under Blast Loading Part II-Experimental Studies. International Journal of Impact Engineering, 24, 975-984. https://doi.org/10.1016/S0734-743X(00)00005-1

[7] Hanssen, A.G., Enstock, L. and Langseth M. (2002) Close-Range Blast Loading of Aluminium Foam Panels. International Journal of Impact Engineering, 27, 593-618. https://doi.org/10.1016/S0734-743X(01)00155-5

[8] Mosallam, A.S. and Nasr, A. (2016) Structural Performance of RC Shear Walls with PostConstruction Openings Strengthened with FRP Composite Laminates. Composite Part B: Engineering, In Press. http://dx.doi.org/10.1016/j.compositesb.2016.06.063

[9] James, A. (1999) Performance Comparison of Plastic Composites with Metals for Vertical Body Panel Applications. SAE Technical Paper.

[10] Kostopoulos, V., Markopoulos, Y.P., Vlachos, D.E., Galiotis, C. and Melanitis, N.E. (2001) A Heavy Duty Composite Bridge Made of Glass Polyester Pultruded Box Beams. Proceedings of RTO Applied Vehicle Technology Panel (AVT) Specialists Meeting on Low Cost Composite Structures, Loen, 7-11 May 2001.

[11] Ramakrishna, S. (1997) Microstructural Design of Composite Materials for Crashworthy Structural Applications. Materials \& Design, 18, 167-173.

https://doi.org/10.1016/S0261-3069(97)00098-8

[12] Mamalis, A.G., Manolakos, D.E., Ioannidis, M.B. and Papapostolou, D.P. (2006) The Static and Dynamic and Axial Collapse of CFRP Square Tubes: Finite Element Modelling. Composite Structures, 74, 213-225. https://doi.org/10.1016/j.compstruct.2005.04.006

[13] Mamalis, A.G., Manolakos, D.E., Ioannidis, M.B. and Papapostolou, D.P. (2005) On the Experimental Investigation of Crack Energy Absorption in Laminate Splaying Collapse Mode of FRP Tubular Components. Composite Structures, 70, 413-429. https://doi.org/10.1016/j.compstruct.2004.09.002

[14] Ramakrishna, S. and Hamada, H. (1998) Energy Absorption Characteristics of Crash Worthy Structural Composite Materials. Key Engineering Materials, 141-143, 585-619. https://doi.org/10.4028/www.scientific.net/KEM.141-143.585

[15] Savona, C.S. and Hogg, P.J. (2006) Effect of Fracture Toughness Properties on the Crushing of Flat Composite Plates. Composites Science and Technology, 66, 2317-2328. https://doi.org/10.1016/j.compscitech.2005.11.038

[16] Sebaey, T.A. and Mahdi, E. (2017) Filler Strengthening of Foam-Filled Energy Absorption Devices Using CFRP Beams. Composite Structures, 160, 1-7. http://dx.doi.org/10.1016/j.compstruct.2016.10.049

[17] Hull, D. (1993) A Unified Approach to Progressive Crushing of Fibre Reinforced Composite Tubes. Composites Science and Technology, 35, 231-246.

[18] Abosbaia, A.A.S., Mahdi, E., Hamouda, A.M.S. and Sahari, B.B. (2003) Quasi-Static Axial Crushing of Segmented and Non Segmented Composite Tubes. Composite Structures, 60, 327-343. https://doi.org/10.1016/S0263-8223(02)00341-0 
[19] Mamalis, A.G., Manolakos, D.E., Ioannidis, M.B. and Papapostolou, D.P. (2004) Crashworthy Characteristics of Axially Statically Compressed Thin-Walled Square CFRP Composite Tubes: Experimental. Composite Structures, 63, 347-360. https://doi.org/10.1016/S0263-8223(03)00183-1

[20] Farley, G. and Jones, R. (1992) Crushing Characteristics of Continuous Fibre Reinforced Composite Tubes. Journal of Composite Materials, 26, 37-50. https://doi.org/10.1177/002199839202600103

[21] Mamalis, A.G., Manolakos, D.E. and Viegelahn, G.L. (1990) Crashworthy Behaviour of Thin-Walled Tubes of Fibreglass Composite Material Subjected to Axial Loading. Journal of Composite Materials, 24, 72. https://doi.org/10.1177/002199839002400104

[22] Macaulay, M.A. (1987) Introduction to Impact Engineering. Chapman and Hall, USA. https://doi.org/10.1007/978-94-009-3159-6

[23] Bardi, F.C., Yun, H.D. and Kyriakides, S. (2003) On the Axisymmetric Progressive Crushing of Circular Tubes under Axial Compression. International Journal of Solids and Structures, 40, 3137-3155. https://doi.org/10.1016/S0020-7683(03)00111-2

[24] Lou, H., Yan, Y., Meng, X. and Jin, C. (2016) Progressive Failure Analysis and Energy-Absorbing Experiment of Composite Tubes under Axial Dynamic Impact. Composites Part B: Engineering, 87, 1-11. http://dx.doi.org/10.1016/j.compositesb.2015.10.016

[25] Fairfull, A.H. and Hull, D. (1987) Effect of Specimen Dimensions on the Specific Energy Absorption of Fibre Composite Tubes. Proceedings of ICCM-VI, 36-45.

[26] Farely, G.L. (1986) Effect of Specimen Geometry on the Energy Absorption of Composite Materials. Journal of Composite Materials, 20, 390. https://doi.org/10.1177/002199838602000406

[27] Thronton, P.H. and Edwards, P.J. (1982) Energy Absorption in Composite Tubes. Journal of Composite Materials, 16, 521-545. https://doi.org/10.1177/002199838201600606

[28] Thronton, P.H., Harwood, J.J. and Beardmore, P. (1985) Fiber Reinforced Plastic Composites for Energy Absorption Purposes. Composites Science and Technology, 24, 275-298. https://doi.org/10.1016/0266-3538(85)90026-0

[29] Mamalis, A.G., Manolakos, D.E., Ioannidis, M.B. and Papapostolou, D.P. (2005) On the Response of Thin-Walled CFRP Composite Tubular Components Subjected to Static and Dynamic Axial Compressive Loading: Experimental. Composite Structures, 69, 407-420. https://doi.org/10.1016/j.compstruct.2004.07.021

[30] Mamalis, A.G. and Johnson, W. (1983) The Quasi-Static Crumpling of Thin-Walled Circular Cylinders and Frusta under Axial Compression. International Journal of Mechanical Sciences, 25, 713-732. https://doi.org/10.1016/0020-7403(83)90078-4

[31] Eshkoor, R.A., Oshkovr, S.A., Sulong, A.B., Zulkifili, R., Ariffin, A.K. and Azhari, C.H. (2013) Effect of Trigger Configuration on the Crashworthiness Characteristics of Natural Silk Epoxy Composite Tubes. Composite Part B: Engineering, 55, 5-10. http://dx.doi.org/10.1016/j.compositesb.2013.05.022

[32] Mamalis, A.G., Manolakos, D.E., Demosthenous, G.A. and Ioannidis, M.B. (1996) Energy Absorption Capability of Fibreglass Composite Square Frusta Subjected to Static and Dynamic Axial Collapse. Thin-Walled Structures, 25, 269-295. https://doi.org/10.1016/0263-8231(95)00057-7

[33] Farely, G.L. (1983) Energy Absorption of Composite Materials. Journal of Composite Materials, 17, 167. https://doi.org/10.1177/002199838301700307

[34] Hamada, H., Coppola, J.C., Hull, D., Maekawa, Z. and Sato, H. (1992) Comparison of Energy Absorption of Carbon/Epoxy and Carbon/PEEK Composite Tubes. Composites, 23, 245-252. https://doi.org/10.1016/0010-4361(92)90184-V

[35] Mamalis, A.G., Manolakos, D.E., Ioannidis, M.B. and Papapostolou, D.P. (2005) On the 
Experimental Investigation of Crash Energy Absorption in Laminate Splaying Collapse Mode of FRP Tubular Components. Composite Structures, 70, 413-429. https://doi.org/10.1016/j.compstruct.2004.09.002

[36] Thornton, P.H. (1989) The Crush Behavior of Pultruded Tubes at High Strain Rates. Journal of Composite Materials, 24, 22.

[37] Farley, G.L. and Jones, R.M. (1992) Crushing Characteristics of Composite Tubes with “Near Elliptical” cross Sections. Journal of Composite Materials, 26, 1252. https://doi.org/10.1177/002199839202601203

[38] Elgalai, A.M., Mahdi, E., Hamouda, A.M.S. and Sahari, B.S. (2004) Crushing Response of Composite Corrugated Tubes to Quasi-Static Axial Loading. Composite Structures, 66, 665-671. https://doi.org/10.1016/j.compstruct.2004.06.002

[39] Zarei, H., Kröger, M. and Albertsen, H. (2008) An Experimental and Numerical Crashworthiness Investigation of Thermoplastic Composite Crash Boxes. Composite Structures, 85, 245-257. https://doi.org/10.1016/j.compstruct.2007.10.028

[40] Abdewi, E.F., Sulaiman, S., Hamouda, A.M.S. and Mahdi, E. (2008) Quasi-Static Axial and Lateral Crushing of Radial Corrugated Composite Tubes. Thin-Walled Structures, 46, 320332. https://doi.org/10.1016/j.tws.2007.07.018

[41] Carroll, M., Ellyin, F., Kujawski, D. and Chiu, A.S. (1995) The Rate-Dependent Behaviour of $\pm 55^{\circ}$ Filament-Wound Glass-Fibre/Epoxy Tubes under Biaxial Loading. Composites Science and Technology, 55, 391-403. https://doi.org/10.1016/0266-3538(95)00119-0

[42] Abosbaia, A.A.S., Mahdi, E., Hamouda, A.M.S., Sahari, B.B. and Mokhtar, A.S. (2005) Energy Absorption Capability of Laterally Loaded Segmented Composite Tubes. Composite Structures, 70, 356-373. https://doi.org/10.1016/j.compstruct.2004.08.039

[43] Mahdi, E., Hamouda, A.M.S., Sahari, B.B. and Khalid, Y.A. (2003) Effect of Hybridisation on Crushing Behaviour of Carbon/Glass Fibre Circular-Cylindrical Shells. Journal of Materials Processing Technology, 132, 49-57. https://doi.org/10.1016/S0924-0136(02)00260-1

[44] Palanivelu, S., Paepegem, W., Van Degrieck, J., Kakogiannis, D., Van Ackeren, J., Van Hemelrijck, D., et al. (2010) Comparative Study of the Quasi-Static Energy Absorption of Small-Scale Composite Tubes with Different Geometrical Shapes for Use in Sacrificial Cladding Structures. Polymer Testing, 29, 381-396. https://doi.org/10.1016/j.polymertesting.2010.01.003

[45] Palanivelu, S., Van Paepegem, W., Degrieck, J., Vantomm, J., Kakogiannis, D., Van Ackeren, J., et al. (2011) Crushing and Energy Absorption Performance of Different Geometrical Shapes of Small-Scale Glass/Polyester Composite Tubes under Quasi-Static Loading Conditions. Composite Structures, 93, 992-1007. https://doi.org/10.1016/j.compstruct.2010.06.021

[46] Farely, G.L. (1986) Effect of Fibre and Matrix Maximum Strain Rate on the Energy Absorption of Composite Materials. Journal of Composite Materials, 20, 322. https://doi.org/10.1177/002199838602000401

[47] Desjardins, S.P. et al. (1989) Aircraft Crash Survival Design Guide. USAA VSCOM TR 89-D-22A-E, Vol I-IV, December.

[48] Thornton, P.H. and Jeryan, R.A. (1987) Composite Structure for Automotive Energy Management. Presented at Autocom'87, Dearbon, 1-4 June 1987.

[49] Beardmore, P. and Johnson, C.F. (1986) The Potential for Composites in Structural Automotive Applications. Composites Science and Technology, 26, 251-281.

https://doi.org/10.1016/0266-3538(86)90002-3

[50] Matthews, F.L., Davies, G.A.O., Hitchings, D. and Soutis, C. (2000) Finite Element Modelling of Composite Materials and Structures. Woodhead Published Limited, USA.

[51] Mahdi, E., Hamouda, A.M.S. and Sen, A.C. (2004) Quasi-Static Crushing of Hybrid and 
Non-Hybrid Natural Fibre Composite Solid Cones. Composite Structures, 66, 647-663. https://doi.org/10.1016/j.compstruct.2004.06.001

[52] Meidell, A. (2009) Computer Aided Material Selection for Circular Tubes Designed to Resist Axial Crushing. Thin-Walled Structures, 47, 962-969. https://doi.org/10.1016/j.tws.2009.02.003

[53] Jimenez, M.A., Miravete, A., Larrode, E. and Revuelta, D. (2000) Effect of Trigger Geometry on Energy Absorption in Composite Profiles. Composite Structures, 48, 107-111. https://doi.org/10.1016/S0263-8223(99)00081-1

[54] Bambach, M.R. (2010) Axial Capacity and Crushing of Thin-Walled Metal, Fibre-Epoxy and Composite Metal-Fibre Tubes. Thin-Walled Structures, 48, 440-452. https://doi.org/10.1016/j.tws.2010.01.006

[55] Mahdi, E., Homouda, A.M.S., Mokhtar, A.S. and Majid, D.L. (2005) Many Aspects to Improve Damage Tolerance of Collapsible Composite Energy Absorber Devices. Composite Structures, 67, 175-187. https://doi.org/10.1016/j.compstruct.2004.09.010

[56] Ghasemnejad, H., Hadavinia, H. and Aboutorabi, A. (2010) Effect of Delamination Failure in Crashworthiness Analysis of Hybrid Composite Box Structures. Materials \& Design, 31, 1105-1116. https://doi.org/10.1016/j.matdes.2009.09.043

[57] Hadavinia, H. and Ghasemnejad, H. (2009) Effects of Mode-I and Mode-II Interlaminar Fracture Toughness on the Energy Absorption of CFRP Twill/Weave Composite Box Sections. Composite Structures, 89, 303-314. https://doi.org/10.1016/j.compstruct.2008.08.004

[58] Farley, G.L. (1983) Energy Absorption of Composite Materials. Composite Materials, 17, 167. https://doi.org/10.1177/002199838301700307

[59] Thornton, P.H. (1979) Energy Absorption in Composite Structures. Journal of Composite Materials, 13, 247. https://doi.org/10.1177/002199837901300308

[60] Schmueser, D.W. and Wickliffe, L.E. (1987) Impact Energy Absorption of Continuous Fiber Composite Tubes. Journal of Engineering Materials and Technology, 109, 72-77. https://doi.org/10.1115/1.3225937

[61] Farley, G.L. and Jones, R.M. (1992) Crushing Characteristics of Continuous Fibre-Reinforced Composite Tubes. Journal of Composite Materials, 26, 37. https://doi.org/10.1177/002199839202600103

[62] Thornton, P.H. and Edwards, P.J. (1982) Energy Absorption in Composite Tubes. Journal of Composite Materials, 16, 521. https://doi.org/10.1177/002199838201600606

[63] (1990) PE Fibre Reinforcement Prevents Crush. News Article in British Plastics and Rubber, 10 January 1990.

[64] Hamada, H. and Ramakrishna, S. (1995) Scaling Effects in the Energy Absorption of Carbon-Fiber/PEEK Composite Tubes. Composites Science and Technology, 23, 211-221. https://doi.org/10.1016/0266-3538(95)00081-X

[65] Hamada, H., Ramakrishna, S. and Satoh, H. (1995) Crushing Mechanism of Carbon Fibre/ PEEK Composite Tubes. Composites, 26, 749-755. https://doi.org/10.1016/0010-4361(95)98195-Q

[66] Nilson, S. (1991) Polyetheretherketone Matrix Resins and Composites. International Encyclopedia of Composites, 6, 282.

[67] Mamalis, A.G., Manolakos, D.E., Demosthenous, G.A. and Ioannidis, M.B. (1997) The Static and Dynamic Axial Crumbling of Thin-Walled Fibreglass Composite Square Tubes. Composites Part B, 28, 439-451. https://doi.org/10.1016/S1359-8368(96)00066-2

[68] Naik, N.K. and Ganesh, V.K. (1992) Prediction of On-Axes Elastic Properties of Plain Weave Fabric Composites. Composite Science and Technology, 45, 135-152. https://doi.org/10.1016/0266-3538(92)90036-3 
[69] Ishikawa, T. and Chou, T.W. (1982) Stiffness and Strength of Woven Fabric Composites. Journal of Materials Science, 17, 3211-3220. https://doi.org/10.1007/BF01203485

[70] Yang, Y.C. and Harding, J. (1990) A Numerical Micromechanics Analysis of the Mechanical Properties of a Plain Weave Composite. Computers and Structures, 36, 839-844. https://doi.org/10.1016/0045-7949(90)90154-T

[71] Whitcomb, J.D. (1991) Three-Dimensional Stress Analysis of Plain Weave Composites. In: O’Brien, T.K., Ed., Composite Materials and Fracture (Vol. 3), ASTM STP 1110, American Society for Testing and Materials, Philadelphia, USA, 417-438. https://doi.org/10.1520/stp17730s

[72] Santulli, C. (2000) Impact Damage Evaluation in Woven Composites Using Acoustic and Thermoelastic Techniques. PhD Thesis, Liverpool University.

[73] Riva, E. (2005) Mechanics of Woven Composites. PhD Thesis, University of Parma, 97-98.

[74] Farley, G.L. (1986) Effect of Specimen Geometry on the Energy Absorption of Composite Materials. Journal of Composite Materials, 20, 390. https://doi.org/10.1177/002199838602000406

[75] Abdewi, E.F. (2016) FRP Composite Tube Subjected to Quasi-Static Axial and Lateral Compression Loadings. Reference Module in Materials Science and Materials Engineering. http://dx.doi.org/10.1016/B978-0-12-803581-8.04081-9

[76] Lau, S.T.W., Said, M.R. and Yaakob, M.Y. (2012) On the Effect of Geometrical Designs and Failure Modes in Composite Axial Crushing: A Literature Review. Composite Structures, 94, 803-812. http://dx.doi.org/10.1016/j.compstruct.2011.09.013

[77] Mahdi, E. and Sebaey, T.A. (2014) An Experimental Investigation into Crushing Behavior of Radially Stiffened GFRP Composite Tubes. Thin-Walled Structures, 76, 8-13. https://doi.org/10.1016/j.tws.2013.10.018

[78] Mahdi, E., Hamouda, A.M.S., Sahari, B.B. and Khalid, Y.A. (2003) Effect of Residual Stresses in Filament Wound Laminated Conical Shell. Journal of Materials Processing Technology, 138, 291-296. https://doi.org/10.1016/S0924-0136(03)00087-6

[79] Alkateb, M., Mahdi, E., Hamouda, A.M.S. and Hamdan, M.M. (2004) On the Energy Absorption Capability of Axially Crushed Composite Elliptical Cones. Composite Structures, 66, 495-501. https://doi.org/10.1016/j.compstruct.2004.04.078

[80] Yan, L.B. and Chouw, N. (2013) Crashworthiness Characteristics of Flax Fibre Reinforced Epoxy Tubes for Energy Absorption Application. Materials \& Design, 51, 629-640. https://doi.org/10.1016/j.matdes.2013.04.014

[81] Abdewi, E.F., Sulaiman, S., Hamouda, A.M.S. and Mahdi, E. (2006) Effect of Geometry on the Crushing Behaviour of Laminated Corrugated Composite Tubes. Journal of Materials Processing Technology, 172, 394-399. https://doi.org/10.1016/j.jmatprotec.2005.07.017

[82] Paruka, P. and Shah, M.K.M. (2013) Influence of Axial and Oblique Impact Loads on Crush Response Properties of Square Tube Structures Made with FRP Pultruded Composites. Procedia Engineering, 68, 572-578. https://doi.org/10.1016/j.proeng.2013.12.223

[83] Mahdi, E., Hamouda, A.M.S., Sahari, B.B. and Khalid, Y.A. (2003) Experimental Quasi Static Crushing of Cone-Tube-Cone Composite System. Compos Part B, 34, 285-302. https://doi.org/10.1016/S1359-8368(02)00102-6

[84] Mahdi, E., Sahari, B.B., Hamouda, A.M.S. and Khalid, Y.A. (2001) An Experimental Investigation into Crushing Behaviour of Filament-Wound Laminated Cone-Cone Intersection Composite Shell. Composite Structures, 51, 211-219. https://doi.org/10.1016/S0263-8223(00)00132-X

[85] Czaplicki, M.J., Robertson, R.E. and Thorton, P.H. (1991) Comparison of Bevel and Tulip Triggered Pultruded Tubes for Energy Absorption. Composites Science and Technology, 40, 31. https://doi.org/10.1016/0266-3538(91)90041-M 
[86] Thuis, H.G.S.J. and Metz, V.H. (1993) The Influence of Trigger Configurations and Laminate Lay-Up on the Failure Mode of Composite Crush Cylinders. Composite Structures, 25, 37-43. https://doi.org/10.1016/0263-8223(93)90148-J

[87] Hamada, H. and Ramakrishna, S. (1995) Scaling Effects in the Energy Absorption of Carbon-Fiber/PEEK Composite Tubes. Composites Science and Technology, 55, 211-221. https://doi.org/10.1016/0266-3538(95)00081-X

[88] Dormegnie, D., Coutellier, D., Delsart, D. and Deletombe, E. (2003) Studies of Scale Effects for Crash on Laminated Structures. Applied Composite Materials, 10, 49-61. https://doi.org/10.1023/A:1021196811432

[89] Thronton, P.H. (1979) Energy Absorption in Composite Structures. Journal of Composite Materials, 13, 247. https://doi.org/10.1177/002199837901300308

[90] Othman, A., Abdullah, S., Ariffin, A.K. and Mohamed, N.A.N. (2016) Investigating the Crushing Behavior of Quasi-Static Oblique Loading on Polymeric Foam Filled Pultruded Composite Square Tubes. Composite Part B: Engineering, 95, 493-514. http://dx.doi.org/10.1016/j.compositesb.2016.04.027

[91] Palanivelu, S., Van Paepegem, W., Degrieck, J., Van Ackeren, J., Kakogiannis, D., Van Hemelrijck, D., et al. (2010) Experimental Study on the Axial Crushing Behaviour of Pultruded Composite Tubes. Polymer Testing, 29, 224-234. https://doi.org/10.1016/j.polymertesting.2009.11.005

[92] Saito, H., Chirwa, E.C., Inai, R. and Hamada, H. (2002) Energy Absorption of Braiding Pultrusion Process Composite Rods. Composite Structures, 55, 407-417. https://doi.org/10.1016/S0263-8223(01)00160-X

[93] Farley, G.L. (1991) The Effect of Crushing Speed on the Energy-Absorption Capability of Composite Tubes. Journal of Composite Materials, 25, 1314.

[94] Zhou, G. (1998) The Use of Experimentally-Determined Impact Force as a Damage Measure in Impact Damage Resistance and Tolerance of Composite Structures. Composite Structures, 42, 375-382. https://doi.org/10.1016/S0263-8223(98)00089-0

[95] Cantwell, W.J. and Morton, J. (1991) The Impact Resistance of Composite Materials-A Review. Composites, 22, 347-362. https://doi.org/10.1016/0010-4361(91)90549-V

[96] Abrate, S. (1991) Impact on Laminated Composite Materials. Applied Mechanics Reviews, 44, 155-190. https://doi.org/10.1115/1.3119500

[97] Liu, D. and Malvern, L.E. (1987) Matrix Cracking in Impacted Glass/Epoxy Plates. Journal of Composite Materials, 21, 594-609. https://doi.org/10.1177/002199838702100701

[98] Davies, G.A.O., Hitchings, D. and Zhou, G. (1996) Impact Damage and Residual Strengths of Woven Fabric Glass/Polyester Laminates. Composites Part A, 27A, 1147-1156. https://doi.org/10.1016/1359-835X(96)00083-8

[99] Cantwell, W.J. and Morton, J. (1989) Comparison of the Low and High Velocity Impact Response of CFRP. Composites, 20, 545-551. https://doi.org/10.1016/0010-4361(89)90913-0

[100] Mitrevski, T., Marshall, I.H., Thomson, R.S. and Jones, R. (2006) Low-Velocity Impacts on Preloaded GFRP Specimens with Various Impactor Shapes. Composite Structures, 76, $209-$ 217. https://doi.org/10.1016/j.compstruct.2006.06.033

[101] Aktasß, M., Atas, C., İçten, B.M. and Karakuzu, R. (2009) An Experimental Investigation of the Impact Response of Composite Laminates. Composite Structures, 87, 307-313. https://doi.org/10.1016/j.compstruct.2008.02.003

[102] Hosseinzadeh, R., Shokrieh, M.M. and Lessard, L. (2006) Damage Behaviour of Fiber Reinforced Composite Plates Subjected to Drop-Weight Impacts. Composites Science and Technology, 66, 61-68. https://doi.org/10.1016/j.compscitech.2005.05.025

[103] Sutherland, L.S. and Soares, C.G. (2005) Impact on Low Fibre-Volume, Glass Polyester Rectangular Plates. Composite Structures, 68, 13-22. 
https://doi.org/10.1016/j.compstruct.2004.02.010

[104] Evci, C. and Gülgeç, M. (2012) An Experimental Investigation on the Impact Response of Composite Materials. International Journal of Impact Engineering, 43, 40-51. https://doi.org/10.1016/j.ijimpeng.2011.11.009

[105] Freitas, M. and Reis, L. (1998) Failure Mechanisms on Composite Specimens Subjected to Compression after Impact. Composite Structures, 42, 365-373. https://doi.org/10.1016/S0263-8223(98)00081-6

[106] Evci, C. and Gülgeç, M. (2014) Effective Damage Mechanisms and Performance Evaluation of Ceramic Composite Armors Subjected to Impact Loading. Journal of Composite Materials, 48, 3215-3236. https://doi.org/10.1177/0021998313508594

[107] Sutherland, L.S. and Soares, C.G. (2003) The Effects of Test Parameters on the Impact Response of Glass Reinforced Plastic Using an Experimental Design Approach. Composites Science and Technology, 63, 1-18. https://doi.org/10.1016/S0266-3538(02)00090-8

[108] Mitrevski, T., Marshall, I.H. and Thomson, R. (2006) The Influence of Impactor Shape on the Damage to Composite Laminates. Composite Structures, 76, 116-122. https://doi.org/10.1016/j.compstruct.2006.06.017

[109] Richardson, M.O.W. and Wisheart, M.J. (1996) Review of Low Velocity Impact Properties of Composite Materials. Composites Part A, 27A, 1123-1131. https://doi.org/10.1016/1359-835X(96)00074-7

[110] Shyr, T.W. and Pan, Y.H. (2003) Impact Resistance and Damage Characteristics of Composite Laminates. Composite Structures, 62, 193-203. https://doi.org/10.1016/S0263-8223(03)00114-4

[111] Davies, G.A.O. and Zhang, X. (1994) Impact Damage Prediction in Carbon Composite Structure. International Journal of Impact Engineering, 16, 149-170. https://doi.org/10.1016/0734-743X(94)00039-Y

[112] Belingardi, G. and Vadori, R. (2002) Low Velocity Impact Tests of Laminate Glass-FiberEpoxy Matrix Composite Material Plates. International Journal of Impact Engineering, 27, 213-229. https://doi.org/10.1016/S0734-743X(01)00040-9

[113] Schoeppner, G.A. and Abrate, S. (2000) Delamination Threshold Loads for Low Velocity Impact on Composite Laminates. Composites Part A, 31, 903-915. https://doi.org/10.1016/S1359-835X(00)00061-0

[114] Yang, F.J. and Cantwell, W.J. (2010) Impact Damage Initiation in Composite Materials. Composites Science and Technology, 70, 336-342. https://doi.org/10.1016/j.compscitech.2009.11.004

[115] Liu, D. (2004) Characterization of Impact Properties and Damage Process of Glass/Epoxy Composite Laminates. Journal of Composite Materials, 38, 1425-1442. https://doi.org/10.1177/0021998304042741

[116] Quaresimin, M., Ricotta, M., Martello, L. and Mian, S. (2013) Energy Absorption in Composite Laminates under Impact Loading. Composites Part B, 44, 133-140. https://doi.org/10.1016/j.compositesb.2012.06.020

[117] Zhang, L. (2001) Engineering Plasticity and Impact Dynamic. World Scientific. https://doi.org/10.1142/4857

[118] Abrate, S. (1998) Impact on Composite Structures. Cambridge University Press, Cambridge. https://doi.org/10.1017/CBO9780511574504

[119] Timoshenko, S. (1959) Theory of Plates and Shells. McGraw Hill, New York.

[120] Davies, G. and Morton, J. (1984) Structural Impact and Crashworthiness. 2 Volumes, Elsevier.

[121] Kim, K.J. and Yu, T.X. (1998) Impact Response and Dynamic Failure of Composites and 
Laminate Materials. TTP, Trans-Tech Publications.

[122] Sierakowski, R.L. and Newaz, G.M. (1995) Damage Tolerance in Advanced Composites. Technomic Publishing Company.

[123] Wu, H.Y. and Springer, G.S. (1988) Impact Induced Stresses, Strains and Delaminations in Composite Plates. Journal of Composite Materials, 22, 533-560. https://doi.org/10.1177/002199838802200603

[124] Pang, S.S., Yang, C. and Zhao, Y. (1995) Impact Response of Single-Lap Composite Joints. Composites Engineering, 5, 1011-1027. https://doi.org/10.1016/0961-9526(95)00003-6

[125] Hancox, N.L. (2000) An Overview of the Impact Behaviour of Fibre-Reinforced Composites. In: Reid, S.R. and Zhou, G., Eds., Impact Behaviour of Fibre-Reinforced Composite Materials and Structures, Woodhead Publishing Ltd., Cambridge.

[126] Mamalis, A.G., Robinson, M., Manolakos, D.E., Demosthenous, G.A., Ioannidis, M.B. and Carruthers, J. (1997) Crashworthy Capability of Composite Material Structures. Composite Structures, 37, 109-134. https://doi.org/10.1016/S0263-8223(97)80005-0

[127] Thornton, P.H. (1990) The Crush of Fiber-Reinforced Plastics. In: Cheremisinoff, N.P., Ed., Handbook of Ceramics and Composites Volume 1: Synthesis and Properties, Marcel Dekker Inc., New York, 307-337.

[128] Wang, Y., Feng, J., Wu, J. and Hu, D. (2016) Effects of Fiber Orientation and Wall Thickness on Energy Absorption Characteristics of Carbon-Reinforced Composite Tubes under Different Loading Conditions. Composite Structures, 153, 356-368. http://dx.doi.org/10.1016/j.compstruct.2016.06.033

[129] Berthelot, J.M. (1999) Composite Materials, Mechanical Behaviour and Structural Analysis. Spring-Verlag, New York. https://doi.org/10.1007/978-1-4612-0527-2

[130] Farley, G.L. and Jones, R.M. (1992) Analogy for the Effect of Material and Geometrical Variables on Energy Absorption Capability of Composite Tubes. Journal of Composite Materials, 26, 78. https://doi.org/10.1177/002199839202600105

[131] Jacob, G.C., Fellers, J.F., Simunivic, S. and Starbuck, M. (2002) Energy Absorption in Polymer Composites for Automotive Crashworthiness. Journal of Composite Materials, 36, 813. https://doi.org/10.1177/0021998302036007164

[132] Mamalis, A.G., Manolakos, D.E., Demosthenous, G.A. and Ioannidis, M.B. (1996) Analysis of Failure Mechanisms Observed in Axial Collapse of Thin-Walled Circular Fibreglass Composite Tubes. Thin-Walled Structures, 24, 335-352. https://doi.org/10.1016/0263-8231(95)00042-9

[133] Mamalis, A.G., Manolakos, D.E., Demosthenous, G.A. and Ioannidis, M.B. (1996) The Static and Dynamic Collapse of Fibreglass Composite Automotive Frame Rails. Composite Structures, 34, 77-90. https://doi.org/10.1016/0263-8223(95)00134-4

[134] Czaplicki, M.J., Robertson, R.E. and Thornton, P.H. (1990) Non-Axial Crushing of E-Glass/ Polyester Pultruded Tubes. Journal of Composite Materials, 24, 1077-1100. https://doi.org/10.1177/002199839002401004

[135] Song, H.-W. and Du, X.-W. (2002) Off-Axis Crushing of GFRP Tubes. Composites Science and Technology, 62, 2065-2073. https://doi.org/10.1016/S0266-3538(02)00152-5

[136] Saito, H., Inai, R., Yokoyama, A. and Hamada, H. (2000) Basic Study of Progressive Crushing Mechanism. Key Engineering Materials, 177-180, 321-326. https://doi.org/10.4028/www.scientific.net/KEM.177-180.321

[137] Warrior, N.A., Turner, T.A., Robitaille, F. and Rudd, C.D. (2004) The Effect of Interlaminar Toughening Strategies on the Energy Absorption of Composite Tubes. Composites Part A, 35, 431-437. https://doi.org/10.1016/j.compositesa.2003.11.001

[138] Jacob, G.C., Fellers, J.F., Simunovic, S. and Starbuck, M. (2002) Energy Absorption in Polymer Composites for Automotive Crashworthiness. Journal of Composite Materials, 36, 
813-850. https://doi.org/10.1177/0021998302036007164

[139] Cauchi Savona, S. and Hogg, P.J. (2006) Effect of Fracture Thoughness Properties on the Crushing of Flat Composite Plates. Composites Science and Technology, 66, 2317-2328. https://doi.org/10.1016/j.compscitech.2005.11.038

[140] Solaimurugan, S. and Velmurugan, R. (2007) Influence of Fibre Orientation and Stacking Sequence on Petalling of Glass/Polyester Composite Cylindrical Shell under Axial Compression. International Journal of Solids and Structures, 44, 6999-7020. https://doi.org/10.1016/j.ijsolstr.2007.03.025

[141] Solaimurugan, S. and Velmurugan, R. (2007) Progressive Crushing of Stitched Glass/ Polyester Composite Cylindrical Shells. Composites Science and Technology, 67, 422-437. https://doi.org/10.1016/j.compscitech.2006.09.002

[142] Ghasemnejad, H., Blackman, B.R.K., Hadavinia, H. and Sudall, B. (2008) Experimental Studies on Fracture Characterisation and Energy Absorption of GFRP Composite Box Structure. Composite Structures, 88, 253-261. https://doi.org/10.1016/j.compstruct.2008.04.006

[143] Ghasemnejad, H. and Hadavinia, H. (2010) Off-Axis Crashworthiness Characteristic of Woven Glass/Epoxy Composite Box Structures. Journal of Reinforced Plastics and Composites, 29, 2306-2330. https://doi.org/10.1177/0731684409347807

[144] Ghafari-Namini, N. and Ghasemnejad, H. (2012) Effect of Natural Stitched Composites on the Crashworthiness of Box Structures. Materials \& Design, 39, 484-494. https://doi.org/10.1016/j.matdes.2012.03.025

[145] Rabiee, A. and Ghasemnejad, H. (2016) Effect of Multi Stitched Locations on High Speed Crushing of Composite Tubular Structures. Composite Part B, 100, 164-175.

https://doi.org/10.1016/j.compositesb.2016.06.068

\section{Submit or recommend next manuscript to SCIRP and we will provide best service for you:}

Accepting pre-submission inquiries through Email, Facebook, LinkedIn, Twitter, etc.

A wide selection of journals (inclusive of 9 subjects, more than 200 journals)

Providing 24-hour high-quality service

User-friendly online submission system

Fair and swift peer-review system

Efficient typesetting and proofreading procedure

Display of the result of downloads and visits, as well as the number of cited articles

Maximum dissemination of your research work

Submit your manuscript at: http://papersubmission.scirp.org/

Or contact ojcm@scirp.org 